\title{
Article \\ Study on Inhibition Characteristics of Composite Structure with High-Temperature Heat Pipe and Metal Foam on Gas Explosion
}

\author{
Xiaohong Gui *(D, Haiteng Xue, Junwei Zhu, Xingrui Zhan and Fupeng Zhao \\ School of Emergency Management and Safety Engineering, China University of Mining and Technology, \\ Beijing 100083, China; BQT2110103017@student.cumtb.edu.cn (H.X.); \\ ZQT2110104122@student.cumtb.edu.cn (J.Z.); ZQT2110104115@student.cumtb.edu.cn (X.Z.); \\ ZQT2010104104@student.cumtb.edu.cn (F.Z.) \\ * Correspondence: 201611@cumtb.edu.cn
}

check for updates

Citation: Gui, X.; Xue, H.; Zhu, J.; Zhan, X.; Zhao, F. Study on Inhibition Characteristics of Composite Structure with High-Temperature Heat Pipe and Metal Foam on Gas Explosion. Energies 2022, 15, 1135. https://doi.org/10.3390/en15031135

Academic Editor: Marco Marengo

Received: 3 January 2022

Accepted: 1 February 2022

Published: 3 February 2022

Publisher's Note: MDPI stays neutral with regard to jurisdictional claims in published maps and institutional affiliations.

Copyright: (C) 2022 by the authors. Licensee MDPI, Basel, Switzerland. This article is an open access article distributed under the terms and conditions of the Creative Commons Attribution (CC BY) license (https:// creativecommons.org/licenses/by/ $4.0 /)$.
Abstract: The hazards caused by gas explosion are mainly due to high temperatures and shock waves. It is of great practical significance to explore a device that can restrain these two hazards at the same time. Through the establishment of the gas explosion calculation model, a numerical analysis of the flame propagation in the three types of pipelines, including the empty pipe, the single metal foam pipe, and the high-temperature heat pipe metal foam composite structure, was carried out. The numerical results are compared with the relevant experimental results. The accuracy, rationality, and accuracy of the calculation model is verified. The research results show that that the gas explosion flame propagation develops fastest and accelerates in the empty pipe, followed by a single metal foam pipe. The gas explosion flame in the pipe with the high-temperature heat pipe metal foam composite structure develops the slowest. The composite structure composed of the high-temperature heat pipe and metal foam is an obvious choice to attenuate the temperature and overpressure of gas explosion. The high-temperature heat pipe can rapidly transmit heat in the form of phase change, and metal foam can effectively reduce the explosion pressure wave. The composite structure with the high-temperature heat pipe, and metal foam, destroys the coupling between flame and pressure wave, which acts as a barrier to explosion. It can effectively reduce the energy of flammable and explosive gas in the rear part of the pipeline and restrain the occurrence of the two explosions. The research results provide a scientific basis for the technical application of new, effective anti-explosion devices in coal mines.

Keywords: gas explosion; metal foam; high-temperature heat pipe; propagation rule; explosionsuppression

\section{Introduction}

The process of gas explosion is a chemical and physical process involving the rapid reaction and rapid propagation of gas. Gas is compressed and energy is concentrated in the continuous reaction process. After a certain distance of propagation, a gas propagation detonation phenomenon may arise. Gas explosion releases a lot of heat instantaneously and is accompanied by continuous explosion or multiple explosions. The coupling effect of explosion energy and pressure wave often leads to the increase of disaster degree and action range. Therefore, knowing how to block the propagation of detonation and flame produced by secondary explosion and to transfer the explosion heat in time is very important to inhibit the thermal damage of the explosion. Mine-explosion prevention technology is a passive-disaster prevention technology to control the influence range of gas explosion, inhibit mine continuous explosion, and reduce the damage degree of gas explosion. It is mainly applied to passive disaster control measures after the failure of mine active-disaster prevention technical measures, to inhibit and control the expansion of disasters; it is the last guarantee of mine safety. At present, coal mines mainly use 
flameproof water shed or rock powder shed as means to control or reduce the consequences of a gas explosion. These explosion-proof facilities have limited explosion-suppression effect. Their mechanism is to transfer the heat in the combustion area, cool and terminate the combustion chemical reaction, and finally cause flame-wave quenching. These facilities lack the inhibition effect on the turbulent flow field of explosion energy wave and ignore the coupling thermal effect of flame and shock wave. Therefore, the effect of quenching gas explosion flame and attenuating explosion shock wave is one of the main technical bottlenecks restricting gas-explosion barrier technology. The core scientific problem behind the technical bottleneck is the dual suppression law of the coupling effect of flame and shock wave during explosion. Based on this understanding, basic research on the dual inhibition law of high-temperature heat pipe metal foam composite structure on the coupling of flame and shock wave during explosion is carried out. The high-temperature heat pipe in the composite structure rapidly transfers heat in the form of phase transformation, and metal foam can effectively weaken the blast shock wave. The flame and shock wave can be double-suppressed by the combination of the high-temperature heat pipe and metal foam, and the coupling effect can be weakened. The main purpose of this paper is to explore the restraining law of the high-temperature heat pipe on flame propagation in the gas explosion process, and to reveal the dual inhibition law of the high-temperature heat pipe metal foam composite structure on the coupling of flame and shock wave during an explosion, in order to provide theoretical guidance and a scientific basis for new, effective barrier-blasting devices in coal mine technology.

A gas explosion is a mine-dynamic phenomenon with strong destructive force and a complex mechanism [1,2]. The damage caused by an explosion is mainly caused by shock wave destruction (detonation) and thermal damage (deflagration) [3]. After the explosion, the detonation wave promotes the combustion wave to spread rapidly in the roadway, and the instantaneous high temperature and high pressure seriously endanger the underground working equipment and field workers [4,5]. At the same time, a negative pressure zone forms in the roadway after an explosion, resulting in increased gas emission. In case of high temperatures, it is easy to induce secondary or even multiple explosions [6,7], which enhance the destructiveness of the accident. Therefore, exploring a device that can weaken the damage effect of shock waves and the thermal effect has important practical significance for the safe and efficient production of coal.

Gas explosion-suppression has long been the focus of researchers in relevant disciplines in various countries. Scholars' research on explosion-suppression structure and method has paved the way for coal mine gas explosion-suppression in the future. Zhang et al. [8] used pristine palygorskite powders as a suppression material to suppress the explosion of methane air premixed gas. The composition, porosity, and pyrolysis characteristics of the powder were measured by X-ray diffraction, energy dispersive spectroscopy, $\mathrm{N}_{2}$ adsorption desorption, and thermogravimetry differential scanning calorimetry. The effects of pristine palygorskite powders' concentration on explosion pressure and average flame propagation velocity of $9.5 \%$ methane air premixed gas were tested on a $20 \mathrm{~L}$ spherical explosion system and a $5 \mathrm{~L}$ pipeline explosion system. Wang et al. [9] prepared gluconic acid-modified polyhydroxy montmorillonite inhibitor successfully. The particle size distribution, composition, surface functional groups, and pyrolysis characteristics of pure montmorillonite powder and gluconic acid modified powder were analyzed by laser particle size analyzer and X-ray diffraction, Fourier transform infrared spectroscopy, and thermogravimetry differential scanning calorimetry. In order to reduce the occurrence of gas explosion accidents, Wang et al. [10] discussed the mechanism and effect of ultrasonic water mist inhibiting gas explosion. Based on the EDC combustion model, the experimental results and numerical results are compared and verified. Wang et al. [11] established an experimental system for suppressing methane/air explosion in pipeline by water mist was. The effects of droplet size and pipe size of water mist on explosion were studied. It was found that water mist droplets of $45 \mu \mathrm{m}$ and $100 \mu \mathrm{m}$ in diameter did not inhibit the explosion. Instead, they promoted the explosion. The larger the diameter, the more likely the 
gas is to explode. However, when the droplet diameter of the water mist was greater than $160 \mu \mathrm{m}$, the larger the tube diameter ratio, the more effective it was in reducing the flame propagation velocity and suppressing the gas explosion. In a two-dimensional numerical model, Song et al. [12] investigated the effect of initial droplet size and spray concentration on the suppression. When the initial spray concentration ranged from $\sim 1.5 \mathrm{~kg} / \mathrm{m}^{3}$, the suppression effect of water mist on explosion overpressure was not significant. The suppression effect of the water mist is mainly reflected in the suppression of the explosion flame temperature. When the initial droplet size was in the range of 50-150 $\mu \mathrm{m}$, the flame length was significantly reduced. However, when the initial droplet size was less than $50 \mu \mathrm{m}$ or greater than $150 \mu \mathrm{m}$, the suppression effect on shortening the flame length began to diminish. Edwards and Norris [13] tested various materials and models to find an effective method of suppressing the explosion of combustible gas mixtures. Finally, it was found that foam ceramic components were an effective method. However, during their study, they only described the properties and structural models of foam ceramics and briefly described their applications. Jing et al. [14] designed a two-dimensional pipe model to investigate the effectiveness and mechanism of monodisperse ultrafine water mist with a diameter of $10 \mu \mathrm{m}$ to suppress methane explosion. With the suppression of $160 \mathrm{~g} / \mathrm{m}^{3}$ water mist, the methane explosion at a stoichiometric concentration $(9.5 \%)$ decayed to deflagration. When the water mist concentration was less than $160 \mathrm{~g} / \mathrm{m}^{3}$, the blast wave was slightly attenuated in the fine water mist zone and returned to a stable blast state after passing through the fine water mist zone. The above water mist can effectively suppress the explosion and eventually lead to flame extinction. The critical transition concentration of ultra-fine water mist that attenuates the methane blast to deflagration and the critical extinction concentration of ultra-fine water mist that completely suppresses the blast within the explosion limit were obtained, providing a visual reference for suppressing gas explosion accidents in coal mine tunnels or pipelines. Lu et al. [15] discussed the use of nitrogen in horizontal ducts to prevent blast propagation in order to reduce the damage caused by gas explosions. Thus, the vent was arranged on the top surface of the duct. Two nitrogen nozzles were arranged near and downstream of the vent. The results show that when the nitrogen pressure reaches or exceeds $0.3 \mathrm{MPa}$, the nitrogen injection prevents the explosion from propagating along the duct. At a nitrogen pressure of $0.1 \mathrm{MPa}$, an explosion cannot be prevented. At a nitrogen pressure of $0.2 \mathrm{MPa}$, most experiments prevented explosion propagation but not all. As the nitrogen pressure increases, the prevention of explosion gradually moves forward from the second nozzle to the first nozzle. Injection at low nitrogen pressures prevented the explosion, whereas delayed nitrogen injection may not have prevented the explosion. Li et al. [16] investigated the effect of inert diluents and flammable gases on the flammable limit and limiting oxygen concentration of methane at atmospheric pressure. The experimental results showed that the flammable limit range increased with the addition of $\mathrm{C}_{2} \mathrm{H}_{4} / \mathrm{C}_{2} \mathrm{H}_{6} / \mathrm{CO} / \mathrm{H}_{2}$ mixtures and the explosive hazard of $\mathrm{CH}_{4}$ increased in a parabolic fashion. Under nitrogen dilution conditions, the flammable range gradually decreases. The explosive limit oxygen concentration of methane decreases with the increasing volume fraction of the gas mixture. A sensitivity analysis shows that basic reactions involving reactive radicals and small molecules play a major role in the near-limit kinetics. From a chemical kinetic point of view, the effect of combustible gases on the flammable limit of $\mathrm{CH}_{4}$ is achieved by influencing the competition between chain branching and chain termination reactions. Zhu et al. [17] investigated the overpressure of methane-air explosions in straight, large-scale tunnels. The Computational Fluid Dynamics (CFD) code of Flame Accelerator Simulator (FLACS) was used and verified by experiments on three different scales, and the volume concentration and Blockage Rate (BR) of methane in the air, the tunnel length, and cross section were studied. The combustion of the same methane air mixture produces the same overpressure due to smooth wall roughness before approaching the outlet degree, and the overpressure attenuates approximately linearly on the same slope, independent of the specific tunnel length. A method to describe the characteristics of cross-section is proposed. It is found that the maximum peak overpressure of methane air 
mixture with different lengths in different cross-section tunnels presents different states. The cross-sectional parameters determine the degree of restriction and further control the maximum peak overpressure in the simulated tunnel. The exponential asymptotic model can be used to easily obtain the maximum peak overpressure. Yu et al. [18] discussed the inhibitory effect of porous media and water mist on methane (9.5\% methane) explosion and proved the inhibitory effect of the coupling effect of ultra-fine water mist and porous media on gas explosion. Jiang et al. [19] combined a physical experiment and a numerical simulation, discussed the influence of phosphorus-containing, ultra-fine water mist on methane explosion flame, proved that ultra-fine water mist can significantly reduce flame temperature, and analyzed the suppression reaction mechanism of lean coal flame and the influence of different additives on gas explosion-suppression.

While most of the above studies use liquid or gas as the main material and start with the energy of a gas explosion shock wave to form a flame retardant belt to suppress the subsequent gas explosion flame, this approach has a poor effect on attenuating the destructiveness of the explosion shock wave, and most of these components are disposable and cannot inhibit the secondary explosion. In recent years, the use of porous materials for gas explosion-suppression has become widespread. Its unique pore structure can attenuate the gas explosion shock wave well. However, at present, the research on explosion-suppression mostly focuses on quenching flame or suppressing pressure wave, ignoring the coupling effect of pressure and temperature. At the same time, there is a lack of research on the ability of the changed physical parameters of porous materials to suppress gas explosion.

The hazards caused by gas explosion are mainly due to high temperatures and shock waves. It is of great practical significance to explore a device that can restrain these two hazards at the same time. Metal foam is a new material, and its unique pore structure can attenuate gas explosion shock waves very well. As a new type of heat transfer element, the high-temperature heat pipe can quickly absorb a large amount of heat under hightemperature conditions and destroy the heat storage environment of gas explosion. The combination of the two into a new composite structure can effectively attenuate the shock wave and flame wave of gas explosion, to suppress the explosion. In this paper, the gas explosion and explosion-suppression in the pipeline are numerically simulated; they are then compared with the relevant experimental results to verify the rationality and accuracy of the calculation model. The metal foam with different thicknesses, porosities, and materials is selected for the simulation of explosion-suppression. The relationship between metal foam parameters and their suppression effect is explored from two aspectstemperature and pressure-and the material and properties required for inhibiting the gas explosion effect are obtained. Based on this, the explosion-suppression effect of the composite structure on high-temperature heat pipe collocation with metal foam is discussed. It is of great significance to effectively reduce the casualties and losses caused by explosions and secondary disasters.

\section{Mathematical Model of Gas Explosion}

Restraining gas explosion is a complex physical and chemical process. It is necessary to make some assumptions before simulation, to describe the combustion and explosion process of gas air premixed gas, and to numerically calculate the changes of some variables in the explosion process. The mathematical model is based on the following assumptions:

1. The pipeline is filled with uniform and static gas air mixture, and all gases in the process are ideal gases.

2. The explosion process is transient and the radiation heat transfer is ignored.

3. The influence of volume force is not considered.

4. Viscous dissipation, Soret effect, and Dufour effect are ignored.

5. The process of gas explosion belongs to one-step and one-way irreversible chemical reaction.

6. The specific heat capacity of mixed gas follows the mixing rule. 
7. The pipe wall is rigid. The radiation and heat conduction between the mixed gas and the wall are ignored, and the convective heat transfer between the wall and the fluid is considered.

\subsection{Governing Equation}

This study is an indefinite flow in a two-dimensional Cartesian coordinate system involving the time variable $t$ and the spatial variables $x, y$.

Continuity equation [20]:

$$
\frac{\partial \rho}{\partial t}+\frac{\partial}{\partial x}\left(\rho v_{x}\right)+\frac{\partial}{\partial y}\left(\rho v_{y}\right)=0
$$

In the Equation (1):

$\rho$-Airflow density, $\mathrm{kg} / \mathrm{m}^{3}$.

$v_{x}-\mathrm{x}$-directional partial velocity, $\mathrm{m} / \mathrm{s}$.

$v_{y}-\mathrm{y}$-directional partial velocity, $\mathrm{m} / \mathrm{s}$.

Momentum equations:

$$
\begin{gathered}
\frac{\partial\left(\rho v_{y}\right)}{\partial t}+\frac{\partial\left(\rho v_{y}^{2}\right)}{\partial y}+\frac{\partial\left(\rho v_{x} v_{y}\right)}{\partial x}=-\frac{\partial P}{\partial y}+\frac{\partial S_{\mathrm{yy}}}{\partial y}+\frac{\partial S_{\mathrm{xy}}}{\partial x} \\
\frac{\partial\left(\rho v_{x}\right)}{\partial t}+\frac{\partial\left(\rho v_{x}^{2}\right)}{\partial x}+\frac{\partial\left(\rho v_{x} v_{y}\right)}{\partial y}=-\frac{\partial P}{\partial x}+\frac{\partial S_{\mathrm{xx}}}{\partial x}+\frac{\partial S_{\mathrm{xy}}}{\partial y}
\end{gathered}
$$

In the above equations:

$P$-Pressure, Pa.

$S_{x x} S_{x y} S_{y y}$-Bias stress, Pa.

Energy equations [21]:

$$
\begin{aligned}
& \frac{\partial(\rho E)}{\partial t}+\frac{\partial\left(\rho E v_{y}\right)}{\partial y}+\frac{\partial\left(\rho E v_{x}\right)}{\partial x}=-\frac{\partial\left(P v_{y}\right)}{\partial y}+\frac{\partial\left(S_{\mathrm{yy}} v_{y}\right)}{\partial y}+\frac{\partial\left(S_{\mathrm{xy}} v_{x}\right)}{\partial y}-\frac{\partial\left(P v_{x}\right)}{\partial x}+\frac{\partial\left(S_{\mathrm{xx}} v_{x}\right)}{\partial x}+\frac{\partial\left(S_{\mathrm{xy}} v_{y}\right)}{\partial x} \\
& \text { In the Equation (4): } \\
& \text { E-Internal Energy, J. } \\
& \text { Component equation [21]: }
\end{aligned}
$$

$$
\frac{\partial}{\partial t}\left(\rho Y_{i}\right)+\frac{\partial}{\partial x}\left(\rho v Y_{i}-\frac{\bar{e}}{\sigma_{i}} \frac{\partial Y_{i}}{\partial x}\right)-R_{i}=0
$$

In the Equation (5):

$Y_{i}$-Mass fraction of components.

$R_{i}$ - Rate of chemical reaction generation of components, $\mathrm{kmol} /\left(\mathrm{m}^{3} / \mathrm{s}\right)$.

$\mu_{e}$-Dynamic viscosity coefficient, $\mathrm{kg} /(\mathrm{m} / \mathrm{s})$.

$\sigma_{i}$-Empirical constants.

\subsection{Turbulence Model}

Under the comprehensive consideration of various characteristics of gas explosion and engineering test data, this study adopts standard $k-\varepsilon$ model to calculate the turbulence of gas explosion. This is a two-equation model, which is widely used in engineering. The $k-\varepsilon$ turbulence model can be expressed as:

Turbulent kinetic energy $k$ equation [21]:

$$
\frac{\partial(\rho k)}{\partial t}+\frac{\partial\left(\rho \mathrm{ku}_{i}\right)}{\partial x_{i}}=\frac{\partial}{\partial x_{j}}\left[\left(\mu+\frac{\mu_{t}}{\sigma_{k}}\right) \frac{\partial k}{\partial x_{j}}\right]+G_{k}+G_{b}-\rho \varepsilon-Y_{M}
$$


Dissipation rate $\varepsilon$ equation [21]:

$$
\frac{\partial(\rho \varepsilon)}{\partial t}+\frac{\partial\left(\rho \varepsilon u_{i}\right)}{\partial x_{i}}=\frac{\partial}{\partial x_{j}}\left[\left(\mu+\frac{\mu_{t}}{\sigma_{\varepsilon}}\right) \frac{\partial \varepsilon}{\partial x_{j}}\right]+\frac{C_{1 \varepsilon} \varepsilon}{k}\left(G_{k}+G_{3 \varepsilon} G_{b}\right)-C_{2 \varepsilon} \rho \frac{\varepsilon^{2}}{k}
$$

where $G_{\mathrm{K}}$ is the turbulent kinetic energy generation caused by the average velocity gradient, $\mathrm{J} ; \mu_{t}$ is the turbulent viscosity coefficient, $\mathrm{kg} /(\mathrm{m} / \mathrm{s}) ; G_{b}$ is the generation of turbulent kinetic energy caused by buoyancy, J; and $Y_{M}$ is the contribution of compressible turbulent pulsation expansion. $C_{1 \varepsilon}=1.44 C_{2 \varepsilon}=1.92 C_{\mu}=0.09 \sigma_{k}=1.0$ and $\sigma_{\varepsilon}=1.3$.

\subsection{Combustion Model and Reaction Rate Model}

The reaction mechanism of gas explosion is very complex, and a detailed chemical reaction dynamic mechanism has not been reached in academic circles. In this study, the reaction is simplified as a one-step irreversible reaction. According to the intensity of chemical reaction and the physical state of reactants, Fluent software provides five combustion models for selection, including premixed combustion model, partial premixed combustion model, non-premixed combustion model, component transport model, and component PDF transport equation model.

In this study, the component transport model is selected for simulation. The model is applicable to most combustion reactions. It is generally used to simulate the mixing, transport, and reaction of components in chemical reactions. Its transport equation is [21]:

$$
\frac{\partial\left(\rho Y_{i}\right)}{\partial t}+\nabla\left(\rho v Y_{i}\right)=-\nabla J_{i}+R_{i}+S_{i}
$$

where $Y_{i}$ is the mass fraction of components; $R_{i}$ is the net production rate of components, $\mathrm{kmol} /\left(\mathrm{m}^{3} / \mathrm{s}\right)$; and $S_{i}$ is the additional production rate of components, $\mathrm{kmol} /\left(\mathrm{m}^{3} / \mathrm{s}\right)$.

\subsection{Wall Function}

The inner wall of the pipeline has a certain influence on the propagation of gas explosion because there is a certain degree of roughness on the wall that hinders the movement of the fluid near the wall and causes a certain change in the velocity of the fluid flowing near the wall in the direction perpendicular to the wall. To solve this problem, the non-equilibrium wall equation provided by Fluent software is used. The equation considers the influence of pressure gradient near the pipe wall on fluid flow, which is more suitable for the simulation process of this study.

\subsection{Porous Media Model}

Fluent software provides a complete porous media model. The resistance of fluid flowing in porous media is defined by the empirical formula provided in the software. Its essence is to add a source term representing momentum consumption in the momentum equation. This term consists of two parts, namely, viscosity loss term and inertia loss term. The expression is [21]:

$$
S_{i}=-\left(\sum_{j=1}^{3} D_{i j} \mu u_{j}+\sum_{j=1}^{3} C_{i j} \frac{1}{2} \rho u_{m a g} u_{j}\right)
$$

where $S_{i}$ is the source term in the ith momentum equation. $D$ and $C$ are the given matrix.

In simple and uniform porous media, the following simplified mathematical model is generally adopted [21]:

$$
S_{i}=-\left(\frac{\mu}{K} u_{i}+F \frac{1}{2} \rho u_{m a g} u_{i}\right)
$$

where $K$ is the permeability coefficient of porous medium and $F$ is the inertia coefficient. 


\section{Numerical Simulation Results and Analysis of Flame Wave and Shock Wave in Gas Explosion}

\subsection{Geometric Model and Boundary Conditions}

The underground roadways or pipelines in the laboratory are regular or regular rectangles. During the simulation, the calculation amount of the three-dimensional model is very large, while the regular axisymmetric model can be simplified to the two-dimensional model, which can greatly reduce the calculation amount and has little impact on the authenticity and accuracy of the results. In the simulation calculation, the two-dimensional model has low requirements for various performances of hardware and occupies less memory; moreover, it can intuitively display the simulation calculation results of gas explosion process. In this simulation, a rectangular pipe model with a length of $6.5 \mathrm{~m}$ and a width of $0.3 \mathrm{~m}$ is established, and the thickness of the pipe wall is ignored. The left, upper, and lower sides of the pipe are wall surfaces, and the right side is the pressure outlet automatic ignition, which is set in the middle of the left wall, and the high-temperature heat pipe area is simplified as a convective heat transfer wall. The whole area of the pipeline is filled with methane air premixed gas. Metal foam is set at $3.5 \mathrm{~m}$ away from the ignition point, and 8 physical points are set up, as shown in Figure 1.

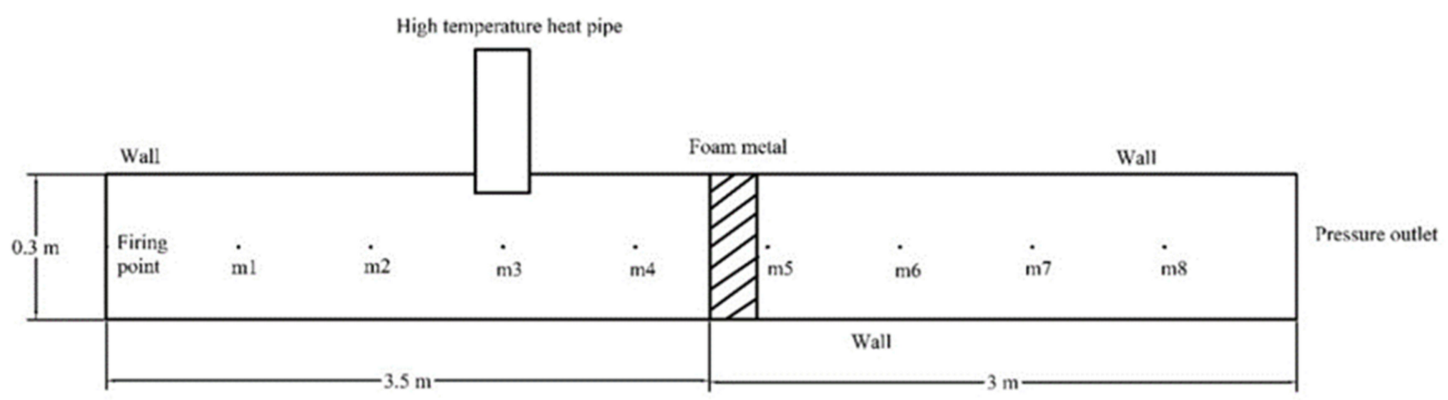

Figure 1. Physical model.

Gambit software is used for grid division. Due to the complexity of the combustion and explosion process of gas air premixed gas, in order to accurately calculate the propagation of flame wave and shock wave in the explosion process, a more detailed grid is used. Considering the calculation accuracy and time, a quadrilateral grid with side length of $5 \mathrm{~mm}$ is adopted. The number of generated structural elements is 32,426. The grid division diagram is shown in Figure 2. Wall boundary conditions are used on the upper, lower, and left sides of the model wall. A constant wall temperature of $300 \mathrm{~K}$ and a non-slip boundary condition are set up. The empirical convection heat transfer coefficient is set up. The right side of the model is set to the pressure outlet. The metal foam area is set to the porous region. The inertial resistance coefficient, viscous resistance coefficient, specific heat capacity, porosity, density, and other related parameters are set. Let the initial time be $t_{0}$, the initial temperature $T\left(t_{0}\right)=300 \mathrm{~K}$, and the initial pressure $P\left(t_{0}\right)=101.325 \mathrm{kPa}$. The partial velocity in $\mathrm{X}$ direction $u_{x}\left(t_{0}\right)=0 \mathrm{~m} / \mathrm{s}$, and the partial velocity in $Y$ direction $v_{y}\left(t_{0}\right)=0 \mathrm{~m} / \mathrm{s}^{-1}$. The concentration of methe air mixture in the pipeline is $9.5 \%$, and the mass fraction of various substances in the mixture is $W_{\mathrm{CH}_{4}}=0.053, W_{\mathrm{O}_{2}}=0.210, W_{\mathrm{H}_{2} \mathrm{O}}=0, W_{\mathrm{CO}_{2}}=0$, and $W_{\mathrm{N}_{2}}=0.737$. 


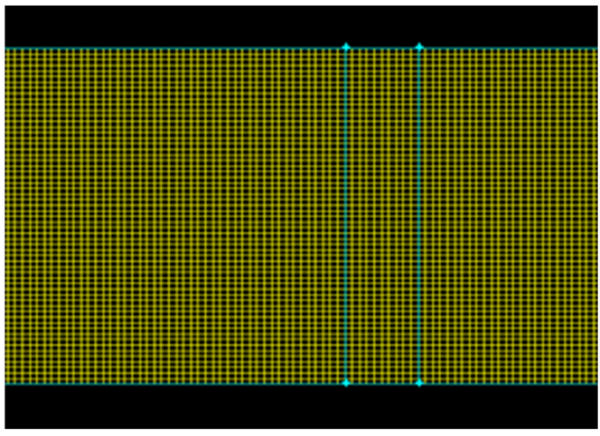

Figure 2. Mesh local.

\subsection{Verification of Numerical Simulation Results}

In order to verify the accuracy of the numerical simulation results of gas explosion, the maximum temperature and overpressure at each monitoring point obtained from the numerical simulation are compared with the measured data in literature [22]. Figures 3 and 4 are the comparisons between the numerical simulation results of the gas explosion for empty pipe and the numerical simulation results of the gas explosion with foam iron in the pipe and the experimental results. This can be seen in Figures 3 and 4.
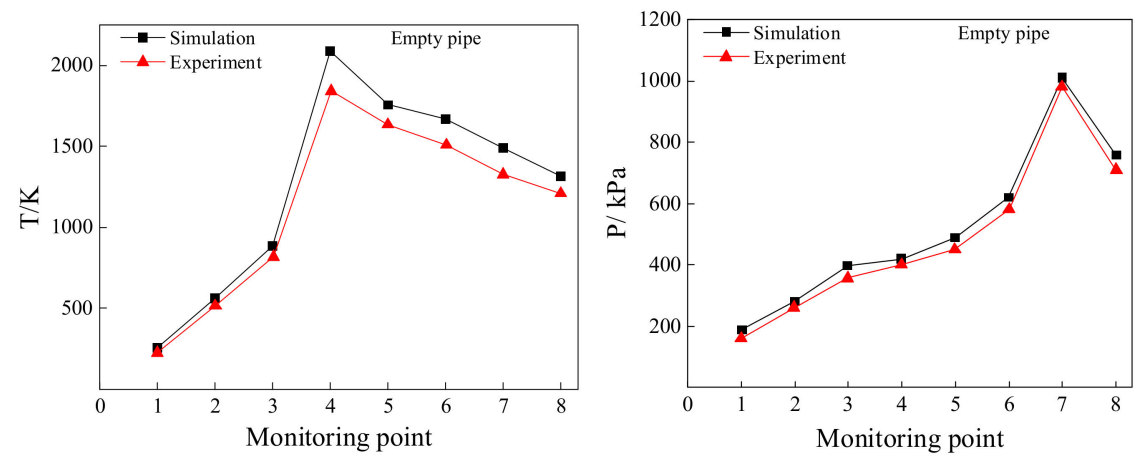

Figure 3. Maximum temperature and overpressure at each monitoring point for empty pipe.
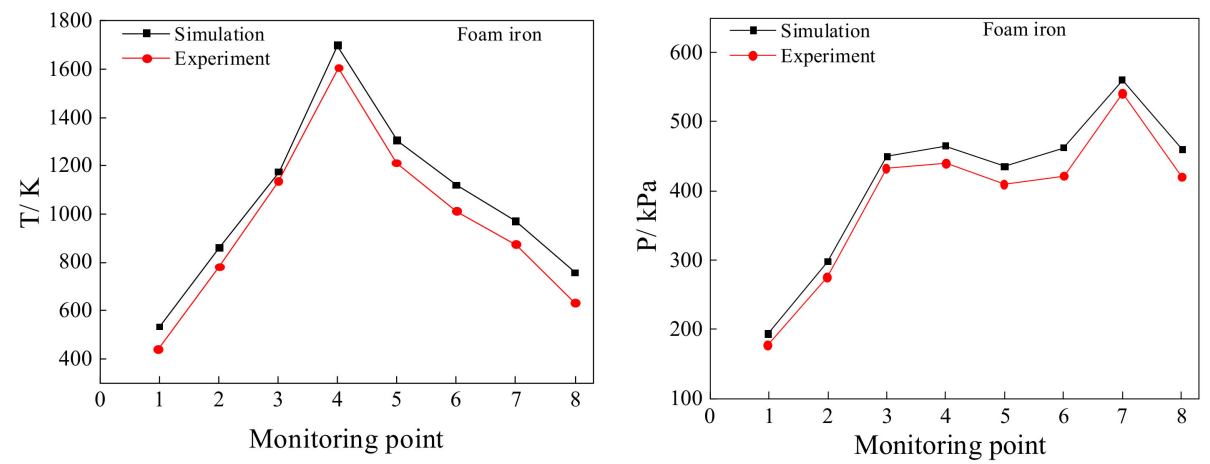

Figure 4. Maximum temperature and overpressure at each monitoring point with foam iron installed in the pipe.

The variation trends of maximum flame temperature and shock wave overpressure at each monitoring point are basically consistent with the experimental results, which shows that the numerical simulation results in this paper are accurate and reliable. However, the simulation results are greater than the experimental results. This is mainly because the steel pipe is used for gas explosion experiment. The steel has certain thermal conductivity, but it is simplified as convective heat transfer wall in the simulation. Although the reaction time is very short, it still leads to a certain degree of error. Due to the limitation of 
installation conditions, the metal foam cross section does not match with the section of the explosive pipe in the experiment, and there is a certain gap. The gas is regarded as an incompressible ideal gas in the numerical simulation. Comparing simulation results and experimental results of empty-pipe gas explosion, the maximum relative error of explosion flame temperature is $8.4 \%$ and the maximum relative error of shock wave overpressure is $9.1 \%$. After adding foam iron, the maximum relative error of flame temperature is $9.3 \%$ and the maximum relative error of shock wave overpressure is $9.8 \%$.

\section{Influence of Metal Foam Material on Gas Explosion Propagation}

Metal foams play a unique role in inhibiting gas explosion due to their good thermal conductivity, strength, and special three-dimensional pore structure. Theoretically, the greater the thickness of the metal foam, the stronger the heat conduction and quenching ability. However, in a practical sense, metal foam is also an obstacle when it is installed in the roadway. The existence of obstacles promotes the formation of explosive turbulence, thus aggravating the intensity of gas explosion. Therefore, it is particularly necessary to study the effect of metal foam with different thicknesses and porosities on the ability of suppressing gas explosion flame wave and shock wave.

\subsection{Geometric Model and Boundary Conditions}

In Section 3.2, the accuracy of the numerical simulation results is verified by comparing the numerical simulation data with the measured data. In order to make the research content more suitable for the actual site, a mine roadway model with length of $100 \mathrm{~m}$ and the section of $3 \mathrm{~m} \times 3 \mathrm{~m}$ is constructed. The metal foam is installed in the center of the roadway. The high-temperature heat pipe is installed before the metal foam and is $20 \mathrm{~m}$ apart from the metal foam. The schematic diagram of roadway model is shown in Figure 5. Distance between monitoring point and ignition point is shown in Table 1 . The left side, the upper side, and the lower side of the roadway are all walls. The right side is the pressure outlet. The middle position of the left wall is automatically ignited. The high-temperature heat pipe area is simplified to the convection heat transfer wall. The whole area of the pipeline is filled with methane air premixed gas. The metal foam is set $50 \mathrm{~m}$ away from the ignition point, and 8 monitoring points are set up.

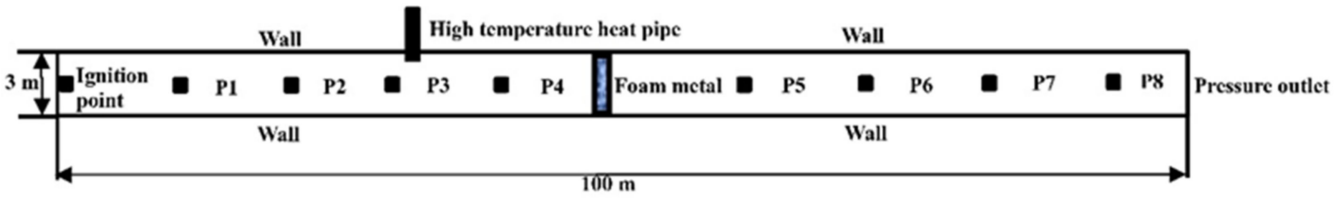

Figure 5. Roadway model.

Table 1. Distance between monitoring point and ignition point.

\begin{tabular}{ccccccccc}
\hline Number of monitoring point & 1 & 2 & 3 & 4 & 5 & 6 & 7 & 8 \\
\hline Distance from ignition point $\mathbf{( m )}$ & 10 & 20 & 30 & 40 & 60 & 70 & 80 & 90 \\
\hline
\end{tabular}

The attenuation rate of the maximum temperature of gas explosion by metal foam is the maximum monitoring temperature of empty pipe minus the maximum monitoring temperature with metal foam installed in the pipe, and the result obtained is then divided by the maximum monitoring temperature of empty pipe.

The attenuation rate of the maximum overpressure of gas explosion by metal foam is the maximum monitoring overpressure of empty pipe minus the maximum monitoring overpressure with metal foam installed in the pipe, and the result obtained is then divided by the maximum monitoring overpressure of empty pipe. 


\subsection{Influence of Thickness of Metal Foam on Propagation of Flame Wave in Gas Explosion}

Figure 6 shows the flame temperature cloud map of foam copper with the porosity of 0.7 under the conditions of different thickness. Metal foam has obvious attenuation effect on gas explosion flame wave and can extinguish gas explosion flame. When the explosion flame passes through the porous material, it is divided into several small flames, making the flame front discontinuous and causing resistance to the flame. The collision and friction with the pore wall lead to a sharp reduction in the number of free radicals participating in the combustion reaction and weaken the reaction intensity. The heat exchange effect between the explosion flame and a large number of pore walls and adjacent structures causes a large amount of heat loss of the flame. The temperature of most small flame drops rapidly below the quenching temperature and goes out, to prevent the continuous propagation of flame. When the porous metal foam is placed, the flame wave in the pipeline is attenuated, and the flame temperature growth trend in the pipeline is obviously lower than that in the tube. The greater the thickness, the stronger the fire resistance and the better the attenuation effect of flame wave. When the metal foam material and the porosity are the same, thick metal foam has good effect on temperature attenuation of gas explosion flame, as shown in Figure 6a-c. Figure 7 shows the shock wave overpressure cloud map of foam copper with the porosity of 0.7 under the conditions of different thickness. The effect of porous metal foam on the shock wave attenuation of gas explosion is obvious, and the maximum overpressure attenuation of the pipeline is obvious after the metal foam is laid. The shock wave reaches the surface of porous metal foam; the reflection of the solid surface of the material consumes part of the shock wave energy; and the pores are compressed on the cross section of the pipeline, thus transforming part of the impact energy into plastic energy. The shock wave entering the porous material causes the pore wall of the porous material to become elastically deformed, so part of the impact energy is transformed into elastic energy. In general, the thick metal foam has good pressure drop effect, the pressure drop effect of metal foam with the thickness of $80 \mathrm{~cm}$ is better than that with the thickness of $60 \mathrm{~cm}$, and the pressure drop effect of metal foam with the thickness of $60 \mathrm{~cm}$ is better than that with the thickness of $40 \mathrm{~cm}$, but the effect of metal foam thickness on overpressure attenuation is not very obvious, as shown in Figure $7 \mathrm{a}-\mathrm{c}$.

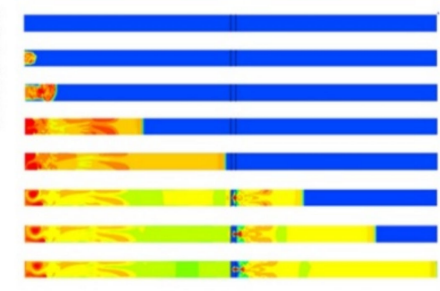

(a) $80 \mathrm{~cm}$

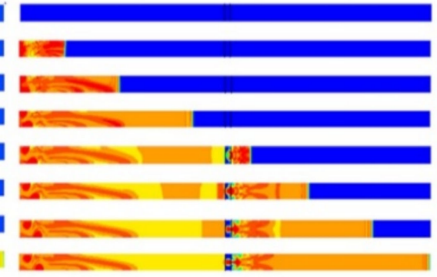

(b) $60 \mathrm{~cm}$

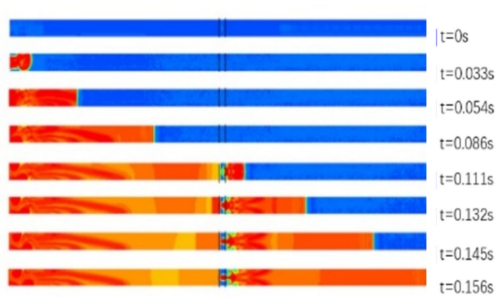

(c) $40 \mathrm{~cm}$

Figure 6. Comparison of temperature cloud of metal foam with different thicknesses.

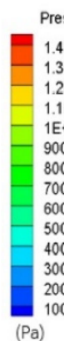

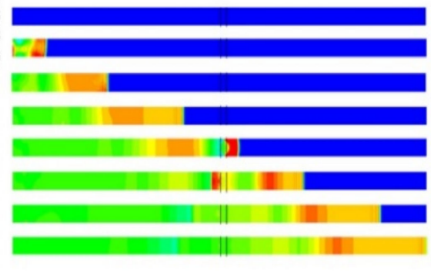

(a) $80 \mathrm{~cm}$

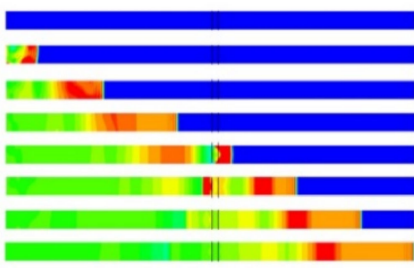

(b) $60 \mathrm{~cm}$

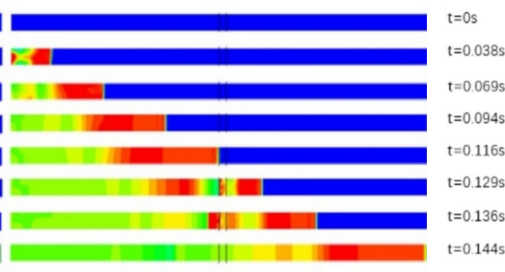

(c) $40 \mathrm{~cm}$

Figure 7. Comparison of pressure cloud of foam metal with different thicknesses. 
1. The foam copper with a thickness of $80 \mathrm{~cm}$ has the best effect to suppress the explosion flame. This is mainly because the greater the thickness, the stronger the heat storage capacity. Meanwhile, the increase of the thickness expands the distance of the flame, the flame is divided into small fire groups for a longer time, and the free radicals of collisional destruction increase in number. Therefore, the increase of thickness can effectively enhance the ability of metal foam to suppress the gas explosion flame wave.

2. The foam copper with a thickness of $80 \mathrm{~cm}$ has the best effect in suppressing the explosion shock wave. This is mainly due to the increase of thickness, making the metal foam have larger volume and specific surface area; colliding and rubbing with the shock wave, playing a better reflection and scattering effect; and ultimately converting the shock wave energy into the elastic, plastic, and internal energy of the material itself. Consequently, the increase of thickness can effectively enhance the ability of metal foam to suppress the blast wave of gas explosion.

Figure 8 is a curve of flame wave temperature varying with time under a porosity of 0.7 and thickness of $40-80 \mathrm{~cm}$. It can be seen from Figure 8 that when the base material is copper, the maximum temperature attenuation rate of the metal foam with a thickness of $80 \mathrm{~cm}$ is $19.2 \%$ higher than that with a thickness of $60 \mathrm{~cm}$, and the maximum temperature attenuation rate of the metal foam with a thickness of $60 \mathrm{~cm}$ is $13.4 \%$ higher than that with a thickness of $40 \mathrm{~cm}$. When the base material is aluminum, the maximum temperature attenuation rate of the metal foam with a thickness of $80 \mathrm{~cm}$ is $17.6 \%$ higher than that with a thickness of $60 \mathrm{~cm}$, and the maximum temperature attenuation rate of the metal foam with a thickness of $60 \mathrm{~cm}$ is $16.1 \%$ higher than that with a thickness of $40 \mathrm{~cm}$. When the base material is iron and the maximum temperature attenuation rate of the metal foam with a thickness of $80 \mathrm{~cm}$ is $15.2 \%$ higher than that with a thickness of $60 \mathrm{~cm}$, the maximum temperature attenuation rate of the metal foam with a thickness of $60 \mathrm{~cm}$ is $14.8 \%$ higher than that with a thickness of $40 \mathrm{~cm}$. It can be seen from Figure 8 that the maximum temperature attenuation rate of the gas explosion flame in the roadway is between $13.4 \%$ and $19.2 \%$, and the flame temperature in the second half of the roadway decreases obviously. The metal foam plate is placed between 4 and 5 of monitoring points, and the flame temperature between 4 and 5 of the monitoring points decreases greatly compared with that of the empty pipe, indicating that the porous metal foam material has good fire suppression effect. When the material and the porosity of metal foam are the same, the greater the thickness of porous metal foam, the better the attenuated flame temperature performance. As the thickness of the porous metal foam increases, the metal components in the matrix material increase, and the explosion shock wave increases the energy consumed by the elastic deformation of the inner structure of the metal foam. The reflection and scattering effect of the shock wave in its internal gap is sufficient, the energy consumption increases, the number of radicals destroyed is increased, the flame temperature is reduced rapidly, and the quenching occurs easily.

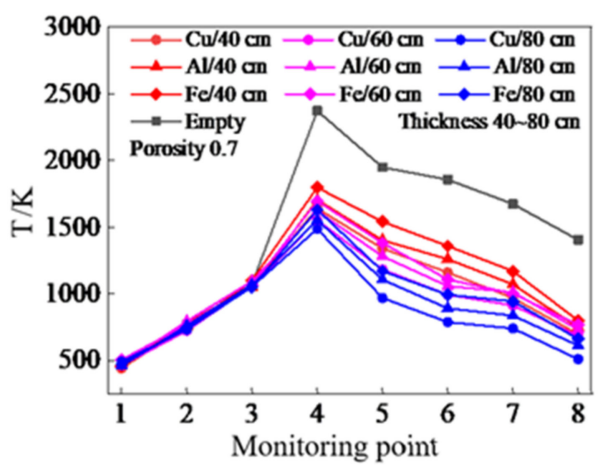

Figure 8. Maximum temperature at each monitoring point. 
Figure 9 is a curve of flame wave temperature under the porosity of 0.8 and thickness of 40-80 cm. It can be seen from Figure 9 that when the base material is copper, the maximum temperature attenuation rate with a thickness of $80 \mathrm{~cm}$ is $17.3 \%$ higher than that with the thickness of $60 \mathrm{~cm}$, and the maximum temperature attenuation rate with a thickness of $60 \mathrm{~cm}$ is $16.8 \%$ higher than that with a thickness of $40 \mathrm{~cm}$. When the base material is aluminum, the maximum temperature attenuation rate with a thickness of $80 \mathrm{~cm}$ is $16.4 \%$ higher than that with the thickness of $60 \mathrm{~cm}$, and the maximum temperature attenuation rate with a thickness of $60 \mathrm{~cm}$ is $15.1 \%$ higher than that with a thickness of $40 \mathrm{~cm}$. When the base material is iron, the maximum temperature attenuation rate with a thickness of $80 \mathrm{~cm}$ is $16.9 \%$ higher than that with the thickness of $60 \mathrm{~cm}$, and the maximum temperature attenuation rate with a thickness of $60 \mathrm{~cm}$ is $14.3 \%$ higher than that with a thickness of $40 \mathrm{~cm}$.

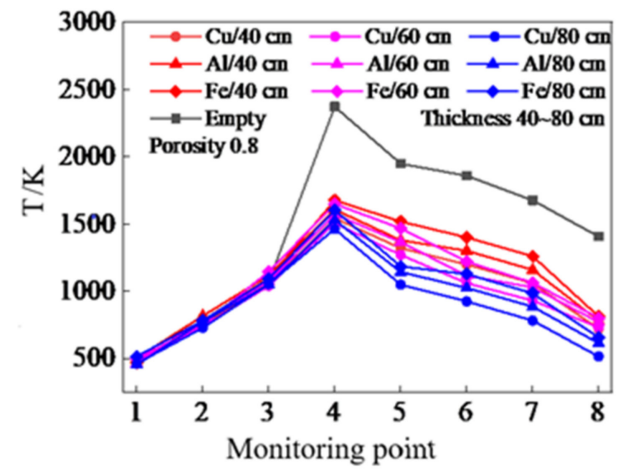

Figure 9. Maximum temperature at each monitoring point.

Figure 10 is a curve of flame wave temperature varying under the porosity of 0.9 and thickness of $40-80 \mathrm{~cm}$. It can be seen from Figure 10 that when the base material is copper, the maximum temperature attenuation rate of the metal foam with a thickness of $80 \mathrm{~cm}$ is $14.7 \%$ higher than that with a thickness of $60 \mathrm{~cm}$, and the metal foam with a thickness of $60 \mathrm{~cm}$ is $13.6 \%$ higher than that with a thickness of $40 \mathrm{~cm}$. When the base material is aluminum, the maximum temperature attenuation rate of the metal foam with a thickness of $80 \mathrm{~cm}$ is $15.5 \%$ higher than that of with a thickness of $60 \mathrm{~cm}$, and the maximum temperature attenuation rate of the metal foam with a thickness of $60 \mathrm{~cm}$ is $12.1 \%$ higher than that with a thickness of $40 \mathrm{~cm}$. When the base material is iron, the maximum temperature attenuation rate of the metal foam with a thickness of $80 \mathrm{~cm}$ is $15.8 \%$ higher than that of the metal foam with a thickness of $60 \mathrm{~cm}$, and the maximum temperature attenuation rate of the metal foam with a thickness of $60 \mathrm{~cm}$ is $12.7 \%$ higher than that with a thickness of $40 \mathrm{~cm}$.

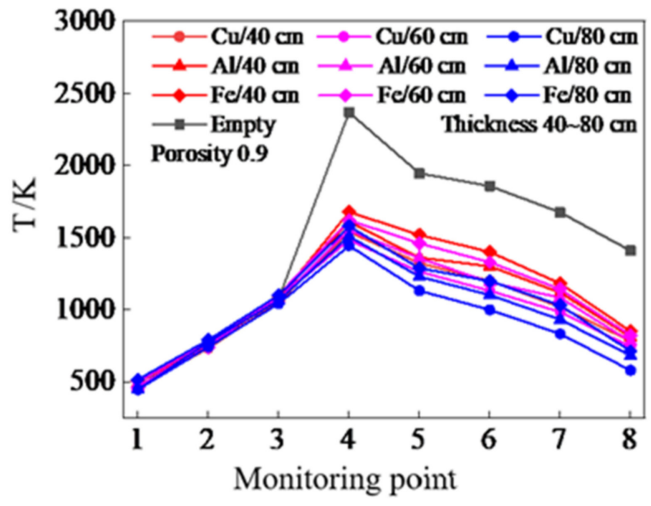

Figure 10. Maximum temperature at each monitoring point. 


\subsection{Influence of Thickness of Metal Foam on Shock Wave Propagation of Gas Explosion}

Figure 11 is the overpressure curve of gas explosion in different metal foams under the condition of porosity of 0.7 and thickness of $40-80 \mathrm{~cm}$. It can be seen from Figure 11 that when the base material is copper, the maximum overpressure attenuation rate of metal foam with thickness of $80 \mathrm{~cm}$ is $8.6 \%$ higher than that with a thickness of $60 \mathrm{~cm}$, and the maximum overpressure attenuation rate of the metal foam with a thickness of $60 \mathrm{~cm}$ is $7.1 \%$ higher than that with a thickness of $40 \mathrm{~cm}$. When the base material is aluminum, the maximum overpressure attenuation rate of the metal foam with a thickness of $80 \mathrm{~cm}$ is $6.8 \%$ higher than that with a thickness of $60 \mathrm{~cm}$, and the maximum overpressure attenuation rate of the metal foam with a thickness of $60 \mathrm{~cm}$ is $7.3 \%$ higher than that with a thickness of $40 \mathrm{~cm}$. When the base material is iron, the maximum overpressure attenuation rate of the metal foam with a thickness of $80 \mathrm{~cm}$ is $8.4 \%$ higher than that with a thickness of $60 \mathrm{~cm}$, and the maximum overpressure attenuation rate of the metal foam with a thickness of $60 \mathrm{~cm}$ is $6.2 \%$ higher than that with a thickness of $40 \mathrm{~cm}$.

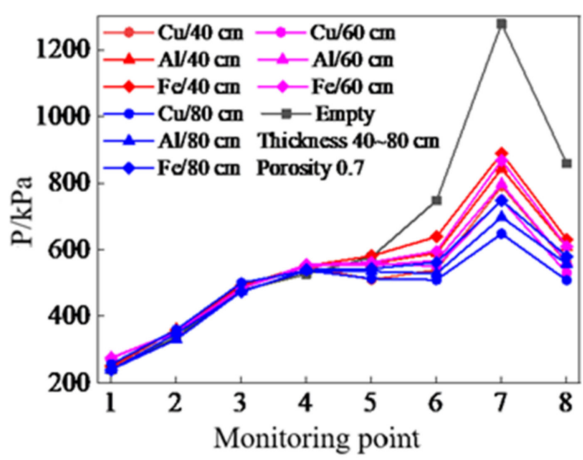

Figure 11. Maximum overpressure at each monitoring point.

Figure 12 is the overpressure curve of gas explosion in different metal foams under the condition of porosity of 0.8 and thickness of $40-80 \mathrm{~cm}$. It can be seen from Figure 12 that when the base material is copper, the maximum overpressure attenuation rate of metal foam with a thickness of $80 \mathrm{~cm}$ is $8.3 \%$ higher than that with a thickness of $60 \mathrm{~cm}$, and the maximum overpressure attenuation rate of the metal foam with a thickness of $60 \mathrm{~cm}$ is $9.1 \%$ higher than that with a thickness of $40 \mathrm{~cm}$. When the base material is aluminum, the maximum overpressure attenuation rate of the metal foam with a thickness of $80 \mathrm{~cm}$ is $6.2 \%$ higher than that with a thickness of $60 \mathrm{~cm}$, and the maximum overpressure attenuation rate of the metal foam with a thickness of $60 \mathrm{~cm}$ is $10.4 \%$ higher than that with a thickness of $40 \mathrm{~cm}$. When the base material is iron, the maximum overpressure attenuation rate of the metal foam with a thickness of $80 \mathrm{~cm}$ is $8.1 \%$ higher than that with a thickness of $60 \mathrm{~cm}$, and the maximum overpressure attenuation rate of the metal foam with a thickness of $60 \mathrm{~cm}$ is $7.7 \%$ higher than that with a thickness of $40 \mathrm{~cm}$.

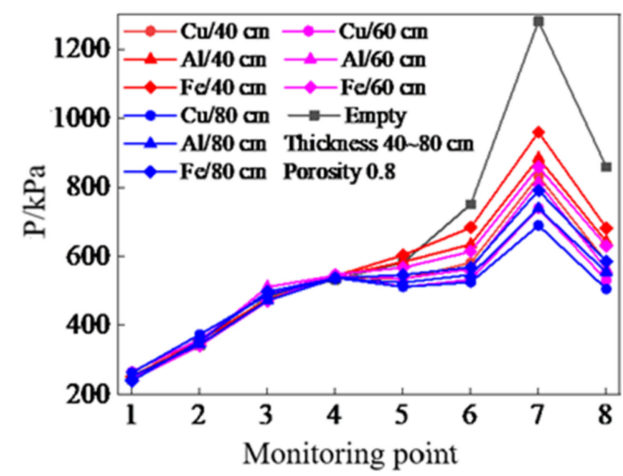

Figure 12. Maximum overpressure at each monitoring point. 
Figure 13 is the overpressure curve of gas explosion in different metal foams under the condition of porosity of 0.8 and thickness of $40-80 \mathrm{~cm}$. It can be seen from Figure 13 that when the base material is copper, the maximum overpressure attenuation rate of metal foam with a thickness of $80 \mathrm{~cm}$ is $6.3 \%$ higher than that with a thickness of $60 \mathrm{~cm}$, and the maximum overpressure attenuation rate of the metal foam with a thickness of $60 \mathrm{~cm}$ is $9.3 \%$ higher than that with a thickness of $40 \mathrm{~cm}$. When the base material is aluminum, the maximum overpressure attenuation rate of the metal foam with a thickness of $80 \mathrm{~cm}$ is $5.8 \%$ higher than that with a thickness of $60 \mathrm{~cm}$, and the maximum overpressure attenuation rate of the metal foam with a thickness of $60 \mathrm{~cm}$ is $9.4 \%$ higher than that with a thickness of $40 \mathrm{~cm}$. When the base material is iron, the maximum overpressure attenuation rate of metal foam with a thickness of $80 \mathrm{~cm}$ is $8.1 \%$ higher than that with a thickness of $60 \mathrm{~cm}$, and the maximum overpressure attenuation rate of the metal foam with a thickness of $60 \mathrm{~cm}$ is $8.3 \%$ higher than that with a thickness of $40 \mathrm{~cm}$.

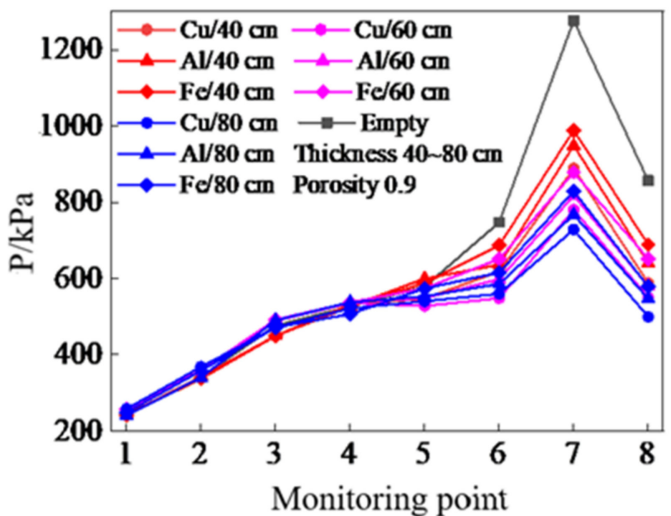

Figure 13. Maximum overpressure at each monitoring point.

To sum up, no matter how porosity and matrix material change, the ability to attenuate the flame temperature and shock wave pressure of gas explosion increases as the thickness of metal foam increases. That is, the thickness of metal material is positively correlated with the ability of attenuation of flame wave and shock wave.

In the pressure figures (Figures 11-13), the overall pressure reaches its maximum at monitoring point 7. Theoretically, the larger the thickness of the metal foam is, the stronger the heat conduction and quenching ability is. However, in a practical sense, the metal foam is also an obstacle when it is installed in the roadway. The existence of obstacles promotes the formation of the explosion turbulence, thus aggravating the intensity of the gas explosion. In case of gas explosion in the pipeline, the maximum pressure of each monitoring point gradually increases with the increase of distance, but due to the existence of the opening on the right side, the maximum temperature gradually decreases from monitoring point 4 and the maximum pressure decreases from monitoring point 7.

\subsection{Influence of Porosity of Metal Foam on Propagation of Flame Wave in Gas Explosion}

Figure 14 shows the flame temperature cloud map of foam copper with the thickness of $40 \mathrm{~cm}$ under the conditions of different porosity. Figure 15 shows the shock wave pressure cloud map of foam copper with the thickness of $40 \mathrm{~cm}$ under the conditions of different porosity. It can be seen from Figures 14 and 15.

1. The metal foam with a porosity of 0.7 has the best effect to suppress the explosion flame. The smaller the porosity is, the more metallic the material is and the smaller the pore size in the metal foam is, which enhances the heat conduction and heat storage performance, and the ability to separate and extinguish the explosion flame is better. Therefore, the smaller the porosity, the stronger the ability of metal foam to suppress the gas explosion flame wave. 
2. The metal foam with a porosity of 0.7 is the best to suppress the blast shock wave. The smaller the porosity, the more metal content exists and smaller pore size in the metal foam is. Thence, the higher the material strength, the higher the energy required to suppress the elastoplastic deformation when the blast wave is applied, and the better the effect of absorbing the energy of the blast wave. Thus, the smaller porosity, the stronger the ability of metal foam to suppress gas explosion shock wave.

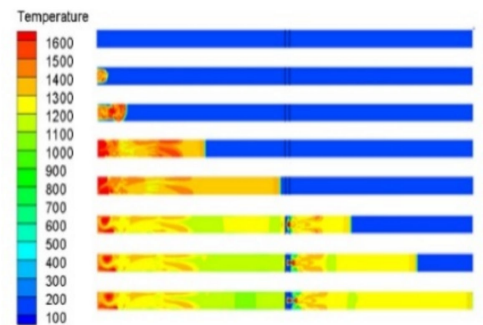

(a) 0.7

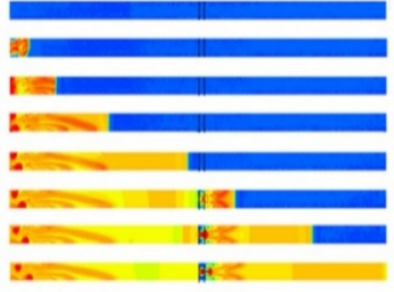

(b) 0.8

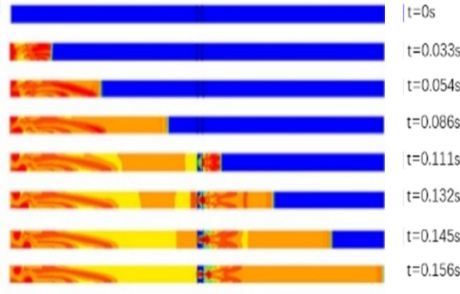

(c) 0.9

Figure 14. Comparison of temperature cloud of metal foam with different porosities.

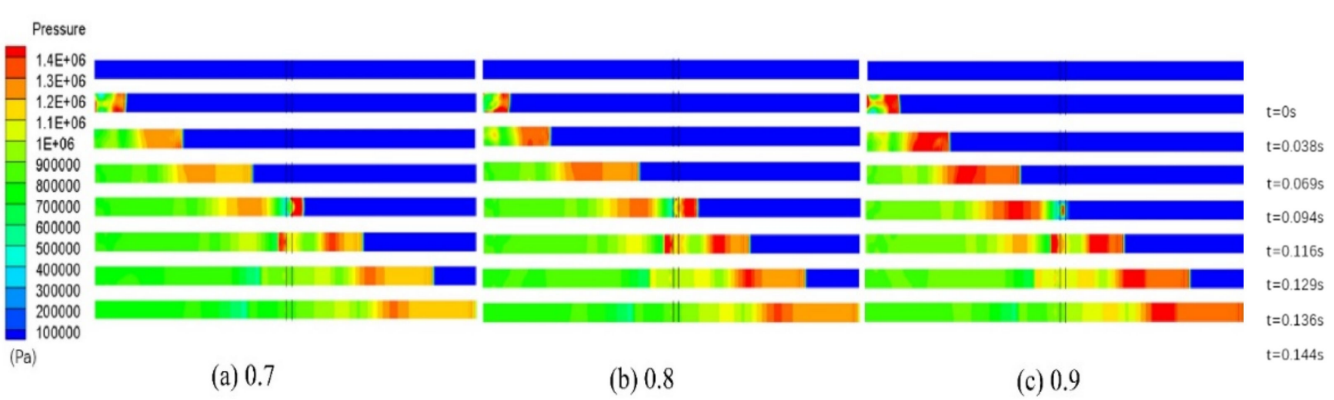

Figure 15. Comparison of pressure cloud of metal foam with different porosities.

Figure 16 shows the flame temperature cloud map with thickness of $40 \mathrm{~cm}$ and porosity of 0.8 under the conditions of different materials. Figure 17 shows the shock wave pressure cloud map with thickness of $40 \mathrm{~cm}$ and porosity of 0.8 , under the conditions of different materials, as shown in Figures 16 and 17.

1. Compared with iron and aluminum, the foam material with copper foam is the best way to suppress the explosion flame. The thermal conductivity of the material has certain effect on its ability to suppress the gas explosion flame wave. The material with better thermal conductivity can lead the heat of the gas explosion flame faster and weaken the gas explosion intensity.

2. Compared with iron and aluminum, the foam material with copper foam is the best way to suppress the blast wave. The energy of the gas explosion shock wave is provided by the flame after the wave. The material has good thermal conductivity and strong ability to suppress the gas explosion flame wave, thereby weakening the energy source of the blast shock wave and ultimately effectively attenuating the gas explosion shock wave. 


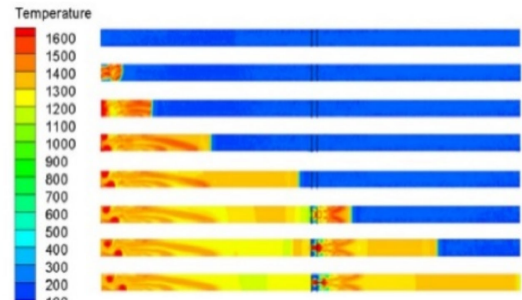

(a) $\mathrm{Cu}$

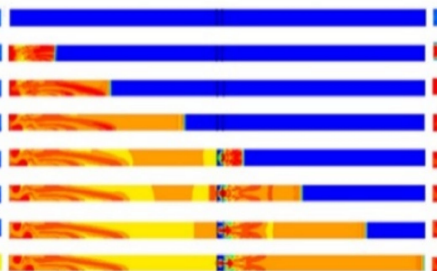

(b) $\mathrm{Al}$

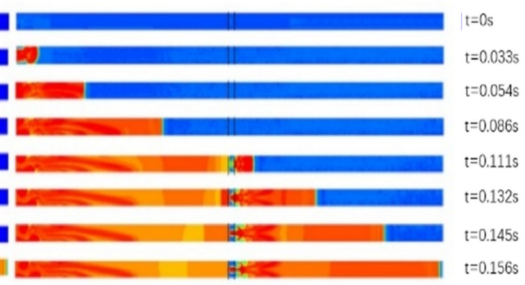

(c) $\mathrm{Fe}$

Figure 16. Comparison of temperature cloud of metal foam with different materials.

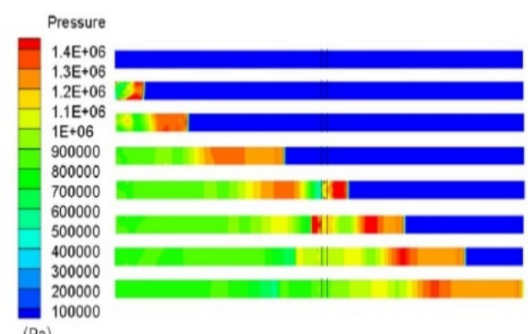

(a) $\mathrm{Cu}$

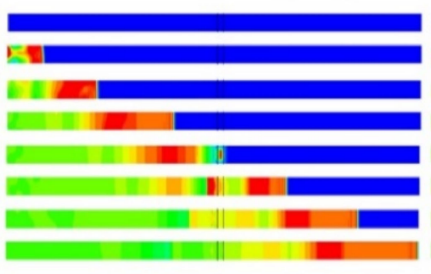

(b) $\mathrm{Al}$

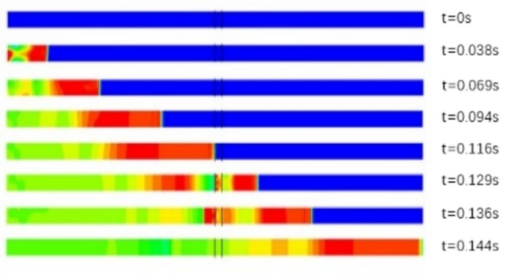

(c) $\mathrm{Fe}$

Figure 17. Comparison of pressure cloud of metal foam with different materials.

Figure 18 shows the flame wave temperature curves of different metal foams with the thickness of $40 \mathrm{~cm}$ and the porosity of $0.7-0.9$. It can be seen from Figure 18 that when the base material is copper, the maximum temperature attenuation rate of metal foam with a porosity of 0.7 is $7.6 \%$ higher than that with porosity of 0.8 , and the maximum temperature attenuation rate of the metal foam with porosity of 0.8 is $6.8 \%$ higher than that with porosity of 0.9. When the base material is aluminum, the maximum temperature attenuation rate of the metal foam with a porosity of 0.7 is $7.4 \%$ higher than that of the metal foam with a porosity of 0.8 , and the maximum temperature attenuation rate of the metal foam with a porosity of 0.8 is $8.1 \%$ higher than that with a porosity of 0.9 . When the base material is iron, the maximum temperature attenuation rate of metal foam with a porosity of 0.7 is $6.1 \%$ higher than that with porosity of 0.8 , and the maximum temperature attenuation rate of the metal foam with porosity of 0.8 is $5.8 \%$ higher than that with porosity of 0.9 .

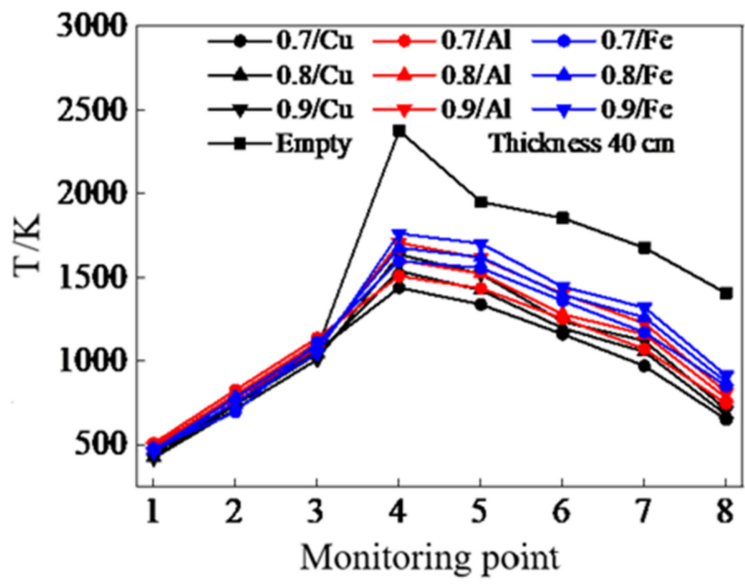

Figure 18. Maximum temperature at each monitoring point.

When the thickness is $40 \mathrm{~cm}$ and the porosity is 0.7 , the maximum temperature attenuation rate of the copper foam is $9.2 \%$ higher than that of the foam aluminum, and the maximum temperature attenuation rate of the foam aluminum is $10.5 \%$ higher than 
that of the foam iron. When the thickness is $40 \mathrm{~cm}$ and the porosity is 0.8 , the maximum temperature attenuation rate of foam copper is $9.7 \%$ higher than that of foam aluminum, and the maximum temperature attenuation rate of foamed aluminum is $11.8 \%$ higher than that of foam iron. When the thickness is $40 \mathrm{~cm}$ and the porosity is 0.9 , the maximum temperature attenuation rate of foam copper is $9.8 \%$ higher than that of foam aluminum, and the maximum temperature attenuation rate of aluminum foam is $11.1 \%$ higher than that of foam iron.

Figure 19 shows the flame wave temperature curves of different metal foams with the thickness of $60 \mathrm{~cm}$ and the porosity of 0.7-0.9. It can be seen from Figure 19 that when the base material is copper, the maximum temperature attenuation rate of the metal foam with a porosity of 0.7 is $6.3 \%$ higher than that with a porosity of 0.8 , and the maximum temperature attenuation rate of metal foam with a porosity of 0.8 is $7.8 \%$ higher than that with a porosity of 0.9 . When the base material is aluminum, the maximum temperature attenuation rate of the metal foam with a porosity of 0.7 thick is $6.6 \%$ higher than that with a porosity of 0.8 , and the maximum temperature attenuation rate of metal foam with a porosity of 0.8 is $5.4 \%$ higher than that with a porosity of 0.9 . When the base material is iron, the maximum temperature attenuation rate of the metal foam with a porosity of 0.7 is $7.1 \%$ higher than that with a porosity of 0.8 , and the maximum temperature attenuation rate of metal foam with a porosity of 0.8 is $8.9 \%$ higher than that with a porosity of 0.9 .

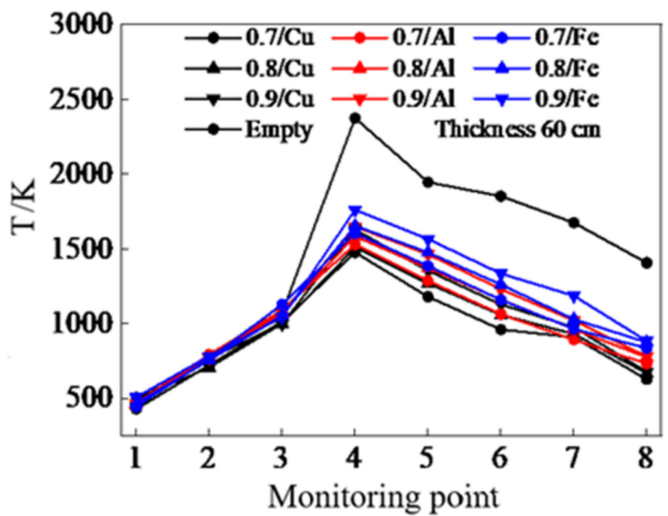

Figure 19. Maximum temperature at each monitoring point.

When the thickness is $60 \mathrm{~cm}$ and the porosity is 0.7 , the maximum temperature attenuation rate of the copper foam is $9.3 \%$ higher than that of the foam aluminum, and the maximum temperature attenuation rate of the foam aluminum is $5.8 \%$ higher than that of the foam iron. When the thickness is $60 \mathrm{~cm}$ and the porosity is 0.8 , the maximum temperature attenuation rate of foam copper is $8.2 \%$ higher than that of foam aluminum, and the maximum temperature attenuation rate of foamed aluminum is $9.1 \%$ higher than that of foam iron. When the thickness is $60 \mathrm{~cm}$ and the porosity is 0.9 , the maximum temperature attenuation rate of foam copper is $8.8 \%$ higher than that of foam aluminum, and the maximum temperature attenuation rate of aluminum foam is $10.7 \%$ higher than that of foam iron.

Figure 20 shows the flame-wave temperature curves of different metal foams with a thickness of $80 \mathrm{~cm}$ and a porosity of $0.7-0.9$. It can be seen from Figure 19 that when the base material is copper, the maximum temperature attenuation rate of the metal foam with a porosity of 0.7 is $10.3 \%$ higher than that with a porosity of 0.8 , and the maximum temperature attenuation rate of metal foam with a porosity of 0.8 is $4.1 \%$ higher than that with a porosity of 0.9 . When the base material is aluminum, the maximum temperature attenuation rate of the metal foam with a porosity of 0.7 thick is $8.9 \%$ higher than that with a porosity of 0.8 , and the maximum temperature attenuation rate of metal foam with a porosity of 0.8 is $5.3 \%$ higher than that with a porosity of 0.9 . When the base material is iron, the maximum temperature attenuation rate of the metal foam with a porosity of 0.7 is 
$8.7 \%$ higher than that with a porosity of 0.8 , and the maximum temperature attenuation rate of metal foam with a porosity of 0.8 is $5.1 \%$ higher than that with a porosity of 0.9 .

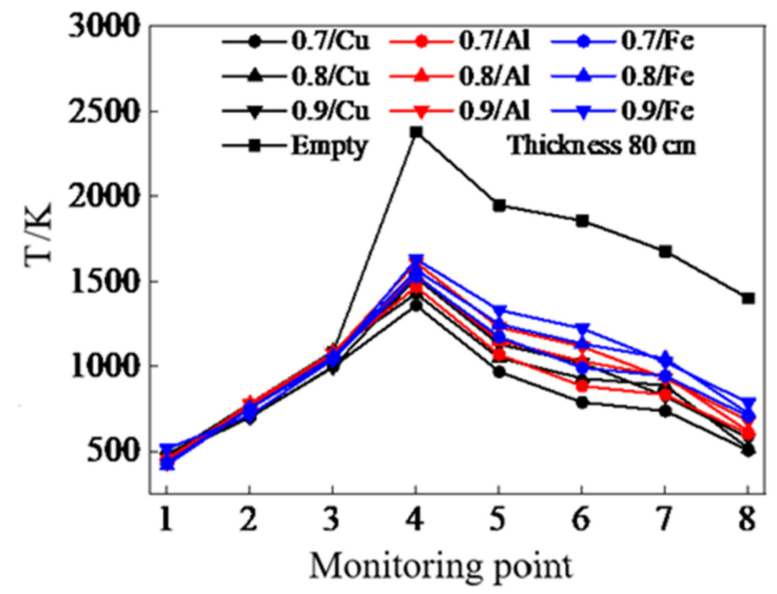

Figure 20. Maximum temperature at each monitoring point.

When the thickness is $80 \mathrm{~cm}$ and the porosity is 0.7 , the maximum temperature attenuation rate of the copper foam is $10.5 \%$ higher than that of the foam aluminum, and the maximum temperature attenuation rate of the foam aluminum is $8.7 \%$ higher than that of the foam iron. When the thickness is $80 \mathrm{~cm}$ and the porosity is 0.8 , the maximum temperature attenuation rate of foam copper is $9.3 \%$ higher than that of foam aluminum, and the maximum temperature attenuation rate of foamed aluminum is $8.4 \%$ higher than that of foam iron. When the thickness is $80 \mathrm{~cm}$ and the porosity is 0.9 , the maximum temperature attenuation rate of foam copper is $6.9 \%$ higher than that of foam aluminum, and the maximum temperature attenuation rate of aluminum foam is $8.1 \%$ higher than that of foam iron.

\subsection{Influence of Porosity of Metal Foam on Shock Wave Propagation of Gas Explosion}

Figure 21 shows the change curve of the shock wave overpressure of different metal foam when the thickness is $40 \mathrm{~cm}$ and the porosity is 0.7-0.9. It can be seen from Figure 21 that when the base material is copper, the maximum overpressure attenuation rate of the metal foam with a porosity of 0.7 is $5.2 \%$ higher than that with a porosity of 0.8 , and the maximum overpressure attenuation rate of metal foam with a porosity of 0.8 is $4.3 \%$ higher than that with a porosity of 0.9 . When the base material is aluminum, the maximum overpressure attenuation rate of the metal foam with a porosity of 0.7 thick is $6.7 \%$ higher than that with a porosity of 0.8 , and the maximum overpressure attenuation rate of metal foam with a porosity of 0.8 is $3.4 \%$ higher than that with a porosity of 0.9 . When the base material is iron, the maximum overpressure attenuation rate of the metal foam with a porosity of 0.7 is $5.8 \%$ higher than that with a porosity of 0.8 , and the maximum overpressure attenuation rate of metal foam with a porosity of 0.8 is $4.6 \%$ higher than that with a porosity of 0.9 .

When the thickness is $40 \mathrm{~cm}$ and the porosity is 0.7 , the maximum overpressure attenuation rate of the copper foam is $6.2 \%$ higher than that of the foam aluminum, and the maximum overpressure attenuation rate of the foam aluminum is $5.1 \%$ higher than that of the foam iron. When the thickness is $40 \mathrm{~cm}$ and the porosity is 0.8 , the maximum overpressure attenuation rate of foam copper is $5.8 \%$ higher than that of foam aluminum, and the maximum overpressure attenuation rate of foamed aluminum is $6.6 \%$ higher than that of foam iron. When the thickness is $40 \mathrm{~cm}$ and the porosity is 0.9 , the maximum overpressure attenuation rate of foam copper is $5.3 \%$ higher than that of foam aluminum, and the maximum overpressure attenuation rate of aluminum foam is $4.6 \%$ higher than that of foam iron. 


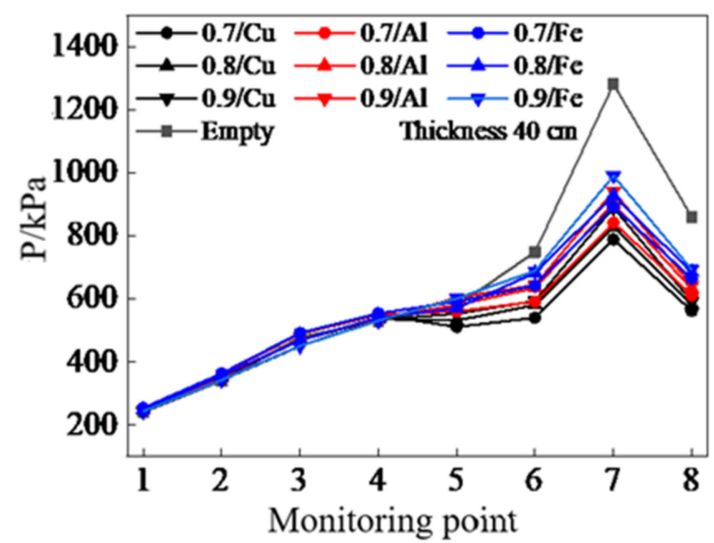

Figure 21. Maximum overpressure at each monitoring point.

Figure 22 shows the change curve of the shock wave overpressure of different metal foam when the thickness is $60 \mathrm{~cm}$ and the porosity is $0.7-0.9$. It can be seen from Figure 22 that when the base material is copper, the maximum overpressure attenuation rate of the metal foam with a porosity of 0.7 is $5.1 \%$ higher than that with a porosity of 0.8 , and the maximum overpressure attenuation rate of metal foam with a porosity of 0.8 is $4.8 \%$ higher than that with a porosity of 0.9 . When the base material is aluminum, the maximum overpressure attenuation rate of the metal foam with a porosity of 0.7 thick is $5.7 \%$ higher than that with a porosity of 0.8 , and the maximum overpressure attenuation rate of metal foam with a porosity of 0.8 is $4.9 \%$ higher than that with a porosity of 0.9 . When the base material is iron, the maximum overpressure attenuation rate of the metal foam with a porosity of 0.7 is $2.3 \%$ higher than that with a porosity of 0.8 , and the maximum overpressure attenuation rate of metal foam with a porosity of 0.8 is $4.5 \%$ higher than that with a porosity of 0.9 .

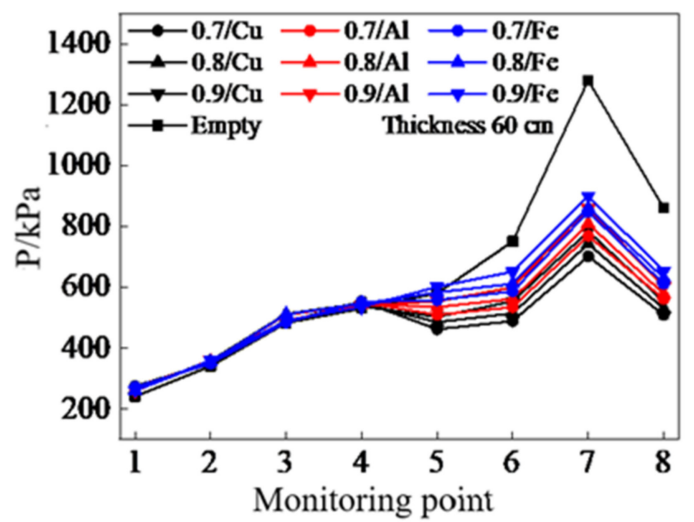

Figure 22. Maximum overpressure at each monitoring point.

When the thickness is $60 \mathrm{~cm}$ and the porosity is 0.7 , the maximum overpressure attenuation rate of the copper foam is $5.1 \%$ higher than that of the foam aluminum, and the maximum overpressure attenuation rate of the foam aluminum is $7.3 \%$ higher than that of the foam iron. When the thickness is $60 \mathrm{~cm}$ and the porosity is 0.8 , the maximum overpressure attenuation rate of foam copper is $6.2 \%$ higher than that of foam aluminum, and the maximum overpressure attenuation rate of foamed aluminum is $5.2 \%$ higher than that of foam iron. When the thickness is $60 \mathrm{~cm}$ and the porosity is 0.9 , the maximum overpressure attenuation rate of foam copper is $4.7 \%$ higher than that of foam aluminum, and the maximum overpressure attenuation rate of aluminum foam is $6.4 \%$ higher than that of foam iron.

Figure 23 shows the change curve of the shock wave overpressure of different metal foam when the thickness is $80 \mathrm{~cm}$ and the porosity is $0.7-0.9$. It can be seen from Figure 23 
that when the base material is copper, the maximum overpressure attenuation rate of the metal foam with a porosity of 0.7 is $3.7 \%$ higher than that with a porosity of 0.8 , and the maximum overpressure attenuation rate of metal foam with a porosity of 0.8 is $4.2 \%$ higher than that with a porosity of 0.9 . When the base material is aluminum, the maximum overpressure attenuation rate of the metal foam with a porosity of 0.7 thick is $7.3 \%$ higher than that with a porosity of 0.8 , and the maximum overpressure attenuation rate of metal foam with a porosity of 0.8 is $3.5 \%$ higher than that with a porosity of 0.9 . When the base material is iron, the maximum overpressure attenuation rate of the metal foam with a porosity of 0.7 is $3.1 \%$ higher than that with a porosity of 0.8 , and the maximum overpressure attenuation rate of metal foam with a porosity of 0.8 is $7.1 \%$ higher than that with a porosity of 0.9 .

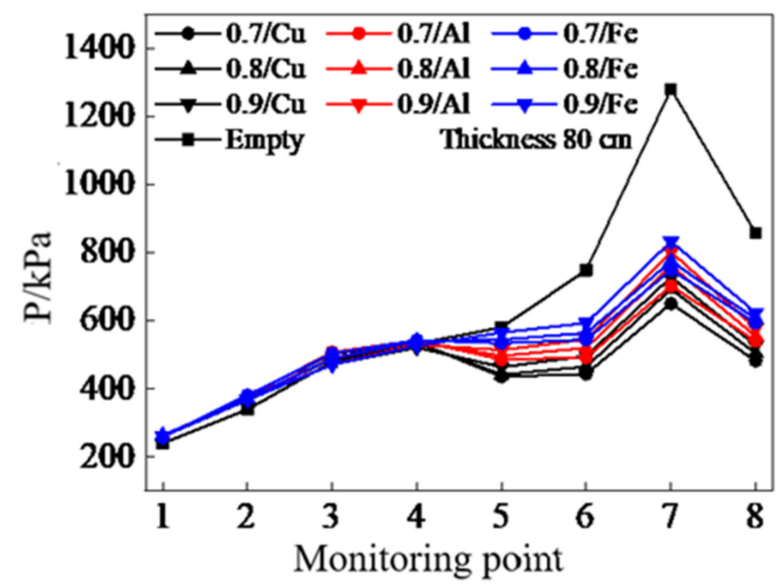

Figure 23. Maximum overpressure at each monitoring point.

When the thickness is $80 \mathrm{~cm}$ and the porosity is 0.7 , the maximum overpressure attenuation rate of the copper foam is $5.4 \%$ higher than that of the foam aluminum, and the maximum overpressure attenuation rate of the foam aluminum is $4.3 \%$ higher than that of the foam iron. When the thickness is $60 \mathrm{~cm}$ and the porosity is 0.8 , the maximum overpressure attenuation rate of foam copper is $5.2 \%$ higher than that of foam aluminum, and the maximum overpressure attenuation rate of foamed aluminum is $4.9 \%$ higher than that of foam iron. When the thickness is $60 \mathrm{~cm}$ and the porosity is 0.9 , the maximum overpressure attenuation rate of foam copper is 3.9\% higher than that of foam aluminum, and the maximum overpressure attenuation rate of aluminum foam is $5.3 \%$ higher than that of foam iron. The influences of material, porosity, and thickness of metal foam on maximum temperature attenuation rate and maximum pressure attenuation rate are shown in Table 2.

The representative curves of pressure versus time for empty pipe and the pipe with $80 \mathrm{~cm}$ copper foam for different porosities installed are shown in Figure 23.

In summary, no matter the thickness of the material and the change of the matrix, with the increase of the thickness of the metal foam and the decrease of porosity, the ability to attenuate the flame temperature and shock wave overpressure of the gas explosion is stronger, that is, the thickness of the metal foam is positively correlated with the ability of the attenuation of flame and shock wave. Porosity is negatively correlated with the ability to attenuate flame and shock wave of gas explosion. Compared with foam aluminum and foam iron, foam copper has the best effect on suppressing blast wave. The energy of the gas explosion shock wave is provided by the flame behind the wave. When the thermal conductivity of the material is higher and the ability to suppress the gas explosion flame wave is greater, the energy source of the explosion shock wave can be weakened to the greatest extent, to effectively attenuate the gas explosion shock wave. 
Table 2. Influence of material, porosity, and thickness of metal foam on propagation of maximum temperature attenuation rate and maximum pressure attenuation rate.

\begin{tabular}{|c|c|c|c|c|}
\hline Material & Porosity & Thickness/cm & $\begin{array}{c}\text { Maximum Temperature } \\
\text { Attenuation Rate } \%\end{array}$ & $\begin{array}{l}\text { Maximum Pressure } \\
\text { Attenuation Rate/\% }\end{array}$ \\
\hline \multirow{6}{*}{$\mathrm{Cu}$} & \multirow{2}{*}{0.7} & $80 / 60$ & $19.2 \%$ & $8.6 \%$ \\
\hline & & $60 / 40$ & $13.4 \%$ & $7.1 \%$ \\
\hline & \multirow{2}{*}{0.8} & $80 / 60$ & $17.3 \%$ & $8.3 \%$ \\
\hline & & $60 / 40$ & $16.8 \%$ & $9.1 \%$ \\
\hline & \multirow{2}{*}{0.9} & $80 / 60$ & $14.7 \%$ & $6.3 \%$ \\
\hline & & $60 / 40$ & $13.6 \%$ & $9.3 \%$ \\
\hline \multirow{6}{*}{$\mathrm{Al}$} & \multirow{2}{*}{0.7} & $80 / 60$ & $17.6 \%$ & $6.8 \%$ \\
\hline & & $60 / 40$ & $16.1 \%$ & $7.3 \%$ \\
\hline & \multirow{2}{*}{0.8} & $80 / 60$ & $16.4 \%$ & $6.2 \%$ \\
\hline & & $60 / 40$ & $15.1 \%$ & $10.4 \%$ \\
\hline & \multirow{2}{*}{0.9} & $80 / 60$ & $15.5 \%$ & $5.8 \%$ \\
\hline & & $60 / 40$ & $12.1 \%$ & $9.4 \%$ \\
\hline \multirow{6}{*}{$\mathrm{Fe}$} & \multirow{2}{*}{0.7} & $80 / 60$ & $15.2 \%$ & $8.4 \%$ \\
\hline & & $60 / 40$ & $14.8 \%$ & $6.2 \%$ \\
\hline & \multirow{2}{*}{0.8} & $80 / 60$ & $16.9 \%$ & $8.1 \%$ \\
\hline & & $60 / 40$ & $14.3 \%$ & $7.7 \%$ \\
\hline & \multirow{2}{*}{0.9} & $80 / 60$ & $15.8 \%$ & $8.1 \%$ \\
\hline & & $60 / 40$ & $12.7 \%$ & $8.3 \%$ \\
\hline \multirow{6}{*}{$\mathrm{Cu}$} & \multirow{2}{*}{40} & $0.7 / 0.8$ & $7.6 \%$ & $5.2 \%$ \\
\hline & & $0.8 / 0.9$ & $6.8 \%$ & $4.3 \%$ \\
\hline & \multirow{2}{*}{60} & $0.7 / 0.8$ & $6.3 \%$ & $5.1 \%$ \\
\hline & & $0.8 / 0.9$ & $7.8 \%$ & $4.8 \%$ \\
\hline & \multirow[b]{2}{*}{80} & $0.7 / 0.8$ & $10.3 \%$ & $3.7 \%$ \\
\hline & & $0.8 / 0.9$ & $4.1 \%$ & $4.2 \%$ \\
\hline \multirow{6}{*}{$\mathrm{Al}$} & \multirow{2}{*}{40} & $0.7 / 0.8$ & $7.4 \%$ & $6.7 \%$ \\
\hline & & $0.8 / 0.9$ & $8.1 \%$ & $3.4 \%$ \\
\hline & \multirow[b]{2}{*}{60} & $0.7 / 0.8$ & $6.6 \%$ & $5.7 \%$ \\
\hline & & $0.8 / 0.9$ & $5.4 \%$ & $4.9 \%$ \\
\hline & \multirow{2}{*}{80} & $0.7 / 0.8$ & $8.9 \%$ & $7.3 \%$ \\
\hline & & $0.8 / 0.9$ & $5.3 \%$ & $3.5 \%$ \\
\hline \multirow{6}{*}{$\mathrm{Fe}$} & \multirow{2}{*}{40} & $0.7 / 0.8$ & $6.1 \%$ & $5.8 \%$ \\
\hline & & $0.8 / 0.9$ & $5.8 \%$ & $4.6 \%$ \\
\hline & \multirow{2}{*}{60} & $0.7 / 0.8$ & $7.1 \%$ & $2.3 \%$ \\
\hline & & $0.8 / 0.9$ & $8.9 \%$ & $4.5 \%$ \\
\hline & \multirow{2}{*}{80} & $0.7 / 0.8$ & $8.7 \%$ & $3.1 \%$ \\
\hline & & $0.8 / 0.9$ & $5.1 \%$ & $7.1 \%$ \\
\hline
\end{tabular}

\section{Numerical Simulation Analysis of High-Temperature Heat Pipe Metal Foam Composite Structure to Restrain Gas Explosion in Roadway}

High-temperature heat pipe, as a new type of heat transfer element, can absorb a lot of heat at high temperature and destroy the thermal storage environment of gas explosion. Combining metal foam and high-temperature heat pipe into a new composite structure can effectively attenuate gas explosion shock wave and flame wave, to achieve the purpose of inhibiting explosion. Through the third collocation study, it is known that the thickness of $80 \mathrm{~cm}$, the porosity of 0.7 , and the material of copper metal foam plate has the strongest inhibition effect on the gas explosion ability. Therefore, the foam copper with the material properties is combined with the high-temperature heat pipe to form a composite explosionsuppression structure, and the numerical simulation of the explosion in the tunnel model is carried out to test the ability of the composite structure to suppress the gas explosion in the roadway model. Figure 24 shows the cloud map of numerical simulation results of gas explosion. Figure 25 is a comparison collocation of gas explosion flame temperature and shock wave overpressure in a composite structure consisting of the empty pipe, the metal foam, and the high-temperature heat pipe with metal foam. 


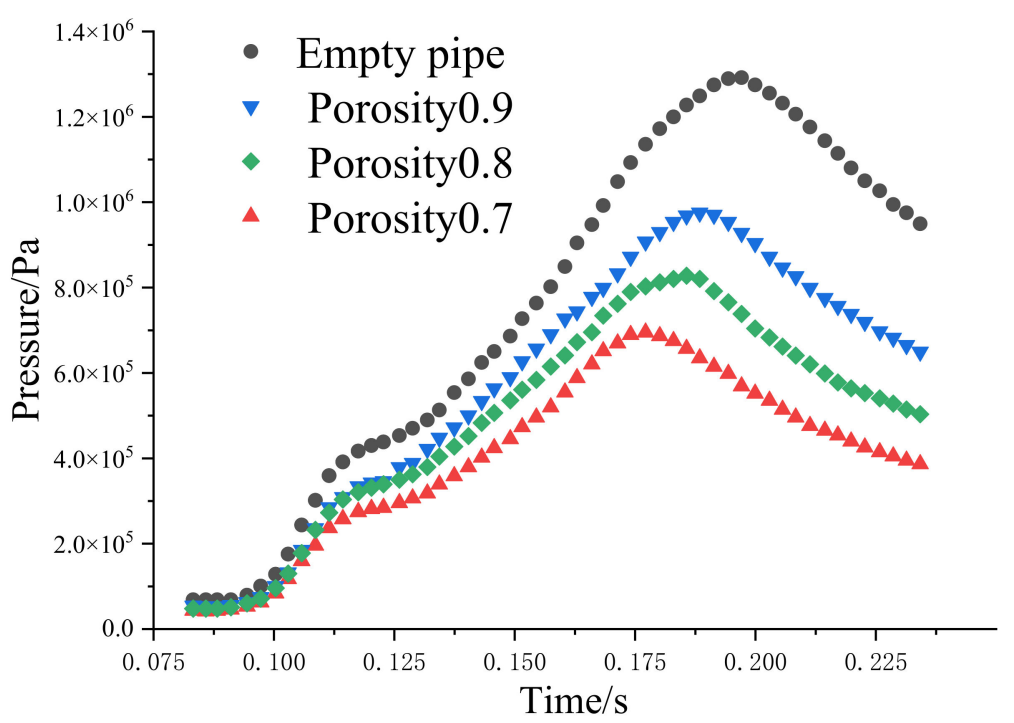

Figure 24. The curves of pressure versus time for empty pipe and the pipe with $80 \mathrm{~cm}$ copper foam for different porosities installed.

As can be seen from Figure 25:

1. After ignition, a semicircular laminar flame is formed near the left wall of the roadway, and the propagation speed is slow. With the development of combustion reaction, the wall effect gradually appears. The flame velocity at the upper and lower walls of the roadway slows down, the flame velocity at the central axis of the roadway is the fastest, and the flame front develops into an ellipse as a whole. With the continuous advancement of the flame, the flame skirt is in constant contact with the wall, resulting in the reduction of the flame surface area and the gradual flattening of the flame front. When the flame front is also near the high-temperature heat pipe area, the high-temperature heat pipe rapidly transfers heat to the outside of the pipeline in the form of gas-liquid phase change, and the flame finally makes contact with the metal foam material. After some obstruction, the flame passes through the metal foam material. The metal foam material has good quenching properties and a certain degree of thermal conductivity. From the color of the cloud map, we can see that the temperature of the flame after the metal foam is significantly reduced, and the overall reaction time is longer than that of the tunnel without the high-temperature heat pipe metal foam composite structure to $0.197 \mathrm{~s}$.

2. The explosion of premixed gas produces a strong shock wave, which rapidly advances towards the opening direction. Due to the existence of wall roughness, the shock wave quickly develops into a plane wave. Due to the heat conduction of the hightemperature heat pipe, the flame temperature decreases, the explosion overpressure decreases to a certain extent, and the propagation speed also slows down. The shock wave then passes through the metal foam area, and the intensity and velocity is again attenuated. The reflection effect of explosive shock wave on the surface of metal foam consumes part of the energy of the shock wave, the internal pore structure is also compressed by force, and the impact energy is transformed into plastic property. The shock wave entering the metal foam causes elastic deformation of the pore structure of the material pore structure and can transform part of the shock wave energy into the elastic property. When the shock wave enters the pore structure, it collides with the wall of the pore structure at various angles, resulting in reflection and scattering at various angles, and the energy of the shock wave is gradually consumed. Under the action of shock wave, metal foam also undergoes shear failure. The impact and friction between the pores and matrix further consume the energy of shock wave. 
3. It can be seen from the gas concentration cloud diagram that after the reaction, the methane concentration in the pipeline is basically zero, which indicates that the combustion reaction is sufficient; all $\mathrm{CH}_{4}$ have participated in the reaction; and, finally, water and carbon dioxide are generated.

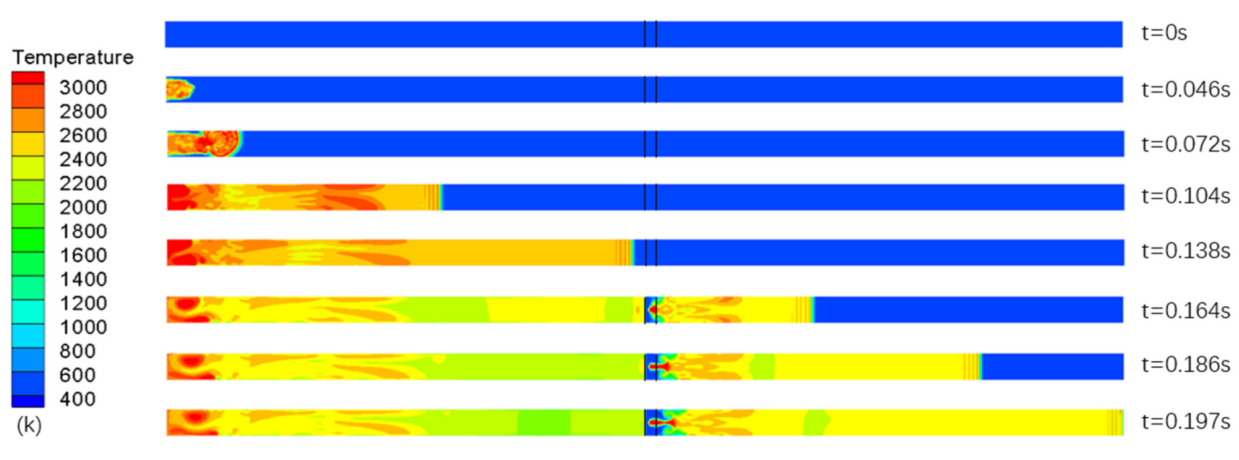

(a)

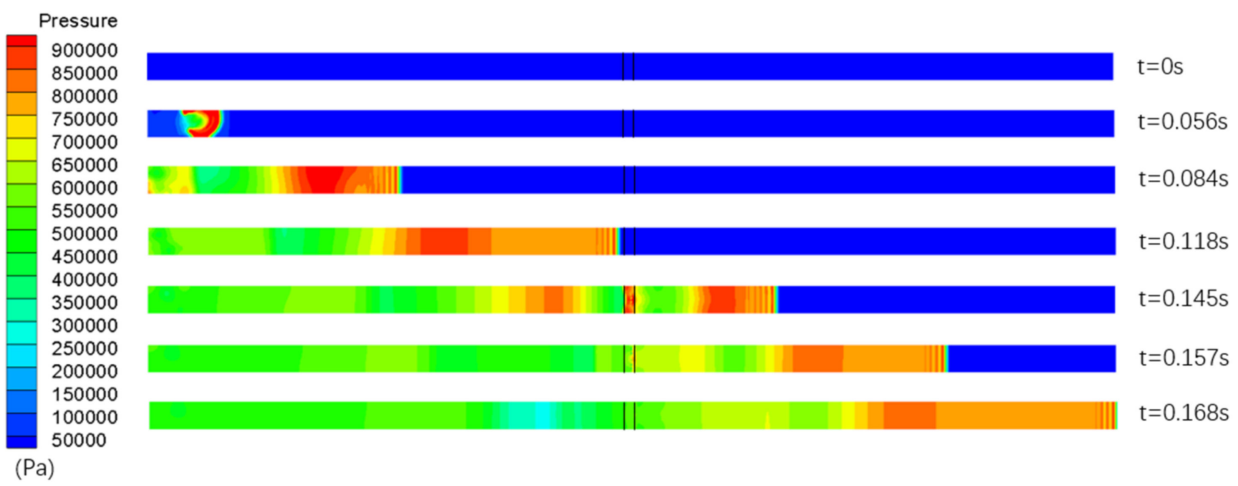

(b)

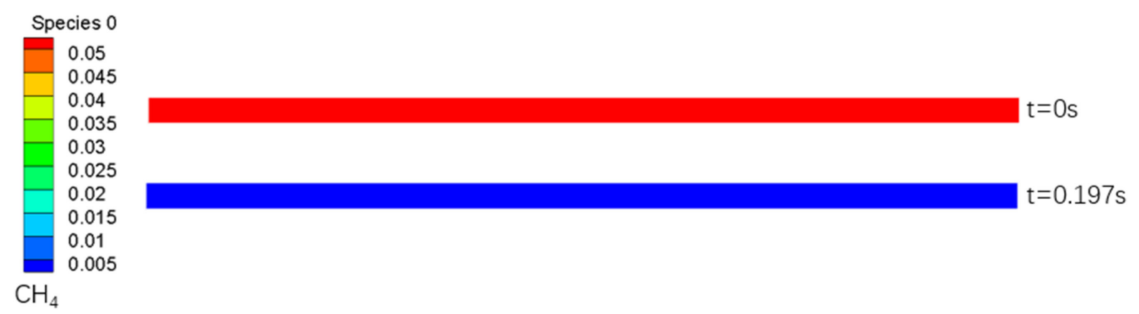

(c)

Figure 25. Numerical simulation results. (a) Flame propagation process; (b) shock wave propagation; and (c) methane reaction process.

As can be seen from Figure 26, the maximum temperature of the gas explosion in the tunnel with metal foam has been reduced by about $36.8 \%$, and the maximum overpressure has been reduced by about $47.3 \%$. The maximum temperature of gas explosion in the roadway with high-temperature heat pipe and metal foam composite structure has been reduced by about $44.7 \%$, and the maximum overpressure has been reduced by about $55.2 \%$. It is indicated that the composite structure composed of metal foam collocation with high- 
temperature heat pipe has better effect on reducing the temperature and overpressure of gas explosion flame.

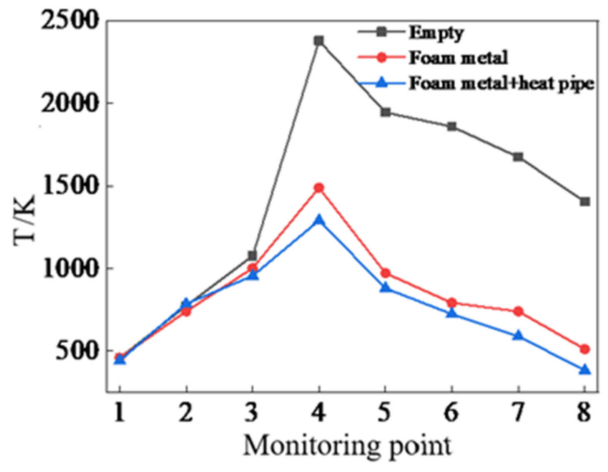

(a)

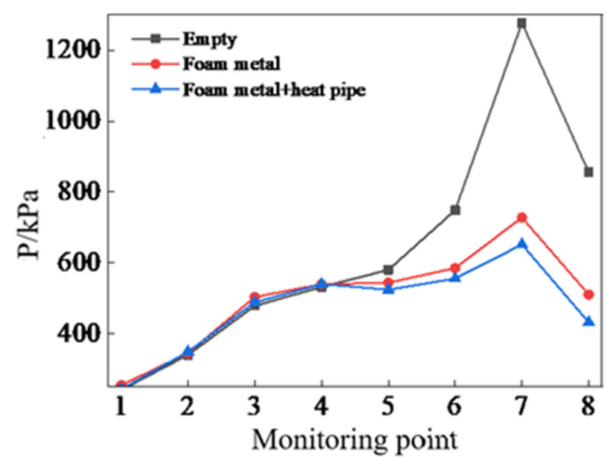

(b)

Figure 26. Maximum temperature and overpressure at each monitoring point. (a) Maximum temperature at each monitoring point; (b) maximum overpressure at each monitoring point.

\section{Conclusions}

The hazards caused by gas explosion mainly lie in high temperature and shock wave. It is of great practical significance to explore a device that can restrain these two hazards at the same time. Metal foam is a new material, and its unique pore structure can attenuate gas explosion shock waves very well. As a new type of heat transfer element, the hightemperature heat pipe can quickly absorb a large amount of heat under high-temperature conditions and destroy the heat storage environment of gas explosion. The combination of the two into a new composite structure can effectively attenuate the shock wave and flame wave of gas explosion, to suppress the explosion. In this paper, the gas explosion and explosion-suppression in the pipeline are numerically simulated; they are then compared with the relevant experimental results to verify the rationality and accuracy of the calculation model. The gas explosion, metal foam, and high-temperature heat pipe metal foam composite structure are used to suppress the gas explosion in the tunnel. Through analysis, the following conclusions can be drawn.

Through the analysis of the gas explosion flame propagation in three different types of pipelines, such as the empty-pipe, single-built metal foam pipe, and high-temperature heat pipe metal foam composite structures, it is concluded that the gas explosion flame propagation develops fastest and accelerates in the air pipe type pipeline, followed by a single built metal foam pipe. The gas explosion flame in the high-temperature heat pipe metal foam composite structure develops the slowest. This composite structure has an obvious effect on suppressing combustion and explosion flame characteristics.

The relationship between physical parameters of metal foam and its ability to suppress explosion is explored. A total of three kinds of thickness of $40 \mathrm{~cm}, 60 \mathrm{~cm}$, and $80 \mathrm{~cm}$ are selected; three porosities of $0.7,0.8$, and 0.9 are selected; and 27 kinds of metal foam of three kinds of materials (copper, aluminum and iron) are simulated in the roadway model. By comparing and analyzing two aspects of temperature and overpressure, the relationship between the physical parameters of metal foam and its explosion-suppression characteristics is obtained. The overpressure value and flame temperature value produced by gas explosion are closely related to the parameters of porous metal foam materials, that is, the greater the thickness, the lower porosity, the better thermal conductivity of materials, and the better the effect of metal foam materials on fire suppression and explosion-suppression, the stronger their ability to suppress gas explosion. The temperature attenuation rate of metal foam with thickness of $80 \mathrm{~cm}$ increased by $14.7 \%-19.2 \%$ compared with that of metal foam with thickness of $60 \mathrm{~cm}$, and the overpressure attenuation rate increased 
by $5.8 \%-8.6 \%$. The temperature attenuation rate of metal foam with thickness of $60 \mathrm{~cm}$ increased by $12.1 \%-13.4 \%$ compared with that of metal foam with thickness of $40 \mathrm{~cm}$, and the overpressure attenuation rate increased by $6.2 \%-10.4 \%$. The temperature attenuation rate of metal foam with porosity of 0.7 increased by $6.1 \%-10.3 \%$ compared with that of 0.8 porosity, and the overpressure attenuation rate increased by $2.3 \%-7.3 \%$. The temperature attenuation rate of metal foam with a porosity of 0.8 higher than that of 0.9 metal foam increased by $4.1 \%-8.9 \%$, and the overpressure attenuation rate increased by $3.4 \%-7.1 \%$. Through comparison and analysis, it is determined that metal foam with $80 \mathrm{~cm}$ thickness and 0.7 porosity and copper foam has the strongest inhibition effect on gas explosion ability.

Metal foam can effectively reduce the explosion flame and shock wave in the tunnel gas explosion-suppression, prolong the reaction time of gas explosion, and slow down the propagation speed of gas explosion. After adding high-temperature heat pipe to form explosion-suppression composite structure, the maximum overpressure attenuation rate and maximum temperature attenuation rate are improved, and the reaction time of gas explosion is further prolonged. The high-temperature heat pipe can rapidly transmit heat in the form of phase change, and metal foam can effectively reduce the explosion pressure wave. Compared with single metal foam, the collocation structure of high-temperature heat pipe with metal foam is more obvious to attenuate the temperature and overpressure of gas explosion flame. Metal foam has the advantages of good thermal performance, high temperature resistance, and strong impact resistance. The heat generated by the reaction reacts with the wall of the pores, causing the number of radicals to drop suddenly, resulting in the interruption of the reaction, thus achieving the purpose of quenching the flame. The high-temperature heat pipe metal foam composite structure destroys the coupling between the flame and pressure wave, which acts as a barrier to explosion. It can effectively reduce the energy of flammable and explosive gas in the rear part of the pipeline and restrain the occurrence of the two explosions.

The numerical simulation results are compared with the relevant experimental data. The variation trends of the maximum temperature and pressure obtained by numerical calculation are in good agreement with the experimental values, and the error is within a reasonable range. Thus, the rationality and accuracy of the gas explosion calculation model in this paper are verified.

Author Contributions: Conceptualization, X.G. and H.X.; methodology, X.G.; software, H.X.; validation, J.Z. and X.Z.; formal analysis, X.G.; investigation, X.G.; resources, X.G.; data curation, H.X.; writing—original draft preparation, H.X.; writing—review and editing, X.Z.; visualization, F.Z.; supervision, X.G.; project administration, X.G.; funding acquisition, H.X. All authors have read and agreed to the published version of the manuscript.

Funding: This research was funded by Fundamental Research Funds for the Central Universities [name of funder] grant number 2021YJSAQ19 and Yueqi Scholar Program for China University of Mining and Technology (Beijing).

Institutional Review Board Statement: Not applicable.

Informed Consent Statement: Not applicable.

Data Availability Statement: Not applicable.

Conflicts of Interest: The authors declare that they have no known competing financial interests or personal relationships that could have influenced the work reported in this paper.

\section{References}

1. Bei, P.; Li, J.; Wang, Y.; Wen, X.; Gao, M. Synergistic inhibition effect on methane/air explosions by $\mathrm{N}_{2}$-twin-fluid water mist containing sodium chloride additive. Fuel 2019, 253, 361-368.

2. Li, X.; Zhang, H.; Yang, C.; Zhao, J.; Long, Y. Effect of Water on the Chain Reaction Characteristics of Gas Explosion. ACS Omega 2021, 6, 12513-12521. [CrossRef] [PubMed]

3. Jiao, Y.; Duan, Y.L.; Zhou, X.Q.; Wang, H.Y. Temporal and spatial distribution of air temperature in tunnel after gas explosion in tunneling. J. Chongqing Univ. 2011, 34, 95-101. 
4. Sun, Y.R.; Yuan, B.; Chen, X.; Li, K.; Wang, L.; Yun, Y.; Ao, F. Suppression of methane/air explosion by kaolinite-based multi-component inhibitor. Powder Technol. 2019, 343, 279-286. [CrossRef]

5. Lu, Y.; Wang, Z.; Cao, X.; Cui, Y.; Sun, P.; Qian, C. Interaction mechanism of wire mesh inhibition and ducted venting on methane explosion. Fuel 2021, 304, 121343. [CrossRef]

6. Nie, B.; Yang, L.; Wang, J. Experiments and Mechanisms of Gas Explosion Suppression with Foam Ceramics. Combust. Sci. Technol. 2016, 188, 2117-2127. [CrossRef]

7. Ywab, C.; Sja, D.; Zw, A.; Hao, S.; Kai, W.; Lei, W. Study on the inhibition influence on gas explosions by metal foam based on its density and coal dust-Science Direct. J. Loss Prevent. Proc. 2018, 56, 451-457.

8. Zhang, Y.M.; Wang, Y.; Zheng, L.G.; Yang, T.; Gao, J.; Li, Z. Effect of Pristine Palygorskite Powders on Explosion Characteristics of Methane-Air Premixed Gas. Energies 2018, 11, 2496. [CrossRef]

9. Wang, Y.; Feng, H.; Zhang, Y.M.; Lin, C.; Han, X. Suppression Effects of Hydroxy Acid Modified Montmorillonite Powders on Methane Explosions. Energies 2019, 12, 4068. [CrossRef]

10. Wang, F.H.; Chen, W.; Wen, X.P.; Zhao, W.L.; Liu, Z.C. Numerical simulation and mechanism analysis of gas explosion suppression by ultrasonic water mist. Energy Source Part A 2019, 41, 2821-2833. [CrossRef]

11. Wang, F.H.; Yu, M.G.; Wen, X.P.; Deng, H.X.; Pei, B. Suppression of methane/air explosion in pipeline by water mist. J. Loss Prevent. Proc. 2017, 49, 791-796. [CrossRef]

12. Song, Y.F.; Zhang, Q. Quantitative research on gas explosion inhibition by water mist. J. Hazard. Mater. 2019, 363, 16-25. [CrossRef]

13. Edwards, K.L.; Norris, M.J. Materials and constructions used in devices to prevent the spread of flames in pipelines and vessels. Mater. Des. 1999, 20, 245-252. [CrossRef]

14. Jing, Q.; Wang, D.; Liu, Q.M.; Chen, X.; Zhong, Y. Inhibition effect and mechanism of ultra-fine water mist on $\mathrm{CH}_{4} /$ air detonation: Quantitative research based on CFD technology. Process Saf. Environ. 2021, 148, 75-92. [CrossRef]

15. Lu, C.; Wang, H.B.; Pan, R.K.; Zhang, Y.P.; Yu, M.G. Preventing the propagation of gas explosion in ducts using spurted nitrogen. Process Saf. Environ. 2019, 123, 11-23. [CrossRef]

16. Li, R.; Zhang, Z.; Si, R.; Wang, L.; Ren, W. Experimental Study on Injuries to Animals Caused by a Gas Explosion in a Large Test Laneway. Shock Vib. 2021, 151, 1-9. [CrossRef]

17. Zhu, Y.F.; Wang, D.M.; Shao, Z.L.; Zhu, X.; Zhang, Y. Investigation on the overpressure of methane-air mixture gas explosions in straight large-scale tunnels. Process Saf. Environ. 2020, 135, 101-112. [CrossRef]

18. Yu, M.; Liu, M.; Wen, X.; Zhao, W.; Pei, B. Experimental study on suppression of methane explosion by porous media and ultra-fine water mist. Fire Saf. Sci. 2010, 19, 51-59. [CrossRef]

19. Jiang, H.; Bi, M.; Huang, L.; Zhou, L.; Gao, W. Suppression mechanism of ultrafine water mist containing phosphorus compounds in methane/coal dust explosions. Energy 2021, 239, 121987. [CrossRef]

20. Abhishek, K.S.; Royb, A.K. Numerical Investigation of Mixed Convection Flows with Variable Viscosity and Prandtl Number and Validation Using ANSYS FLUENT. J. Appl. Comput. Math-Bak 2021, 10, 51-53.

21. Jia, B.S.; Jin, K.; Hu, R.X.; Li, C.M.; Li, Z.X.; Li, S.G. Inhibitory Effect of Porous Media Materials on Characteristics of Gas Explosion in Confined Space. World Sci. Technol. Res. Dev. 2015, 37, 473-476.

22. Wei, C.R. Porous Materials Inhibition on Gas Explosion Degree; Harbin Institute of Technology: Harbin, China, 2012. 